\title{
Pyramidal Neurons Are "Neurogenic Hubs" in the Neurovascular Coupling Response to Whisker Stimulation
}

\author{
Clotilde Lecrux, ${ }^{1,3}$ Xavier Toussay, ${ }^{1,3}$ Ara Kocharyan, ${ }^{1,3 \star}$ Priscilla Fernandes, ${ }^{1,3}$ Sujay Neupane, ${ }^{2,3}$ Maxime Lévesque, ${ }^{3}$ \\ Fabrice Plaisier, ${ }^{4}$ Amir Shmuel, ${ }^{2,3}$ Bruno Cauli, ${ }^{4}$ and Edith Hamel ${ }^{1,3}$ \\ ${ }^{1}$ Laboratory of Cerebrovascular Research, ${ }^{2}$ Brain Imaging Centre, Departments of Neurology and Neurosurgery and Biomedical Engineering, and ${ }^{3}$ Montreal \\ Neurological Institute, McGill University, Montréal, Québec H3A 2B4, Canada, and 4Laboratoire de Neurobiologie des Processus Adaptatifs, Centre \\ National de la Recherche Scientifique and Université Pierre et Marie Curie, 75005 Paris, France
}

The whisker-to-barrel cortex is widely used to study neurovascular coupling, but the cellular basis that underlies the perfusion changes is still largely unknown. Here, we identified neurons recruited by whisker stimulation in the rat somatosensory cortex using double immunohistochemistry for c-Fos and markers of glutamatergic and GABAergic neurons, and investigated in vivo their contribution along with that of astrocytes in the evoked perfusion response. Whisker stimulation elicited cerebral blood flow (CBF) increases concomitantly with c-Fos upregulation in pyramidal cells that coexpressed cyclooxygenase-2 (COX-2) and GABA interneurons that coexpressed vasoactive intestinal polypeptide and/or choline acetyltransferase, but not somatostatin or parvalbumin. The evoked CBF response was decreased by blockade of NMDA (MK-801, -37\%), group I metabotropic glutamate (MPEP+LY367385, -40\%), and GABA-A (picrotoxin, $-31 \%$ ) receptors, but not by GABA-B, VIP, or muscarinic receptor antagonism. Picrotoxin decreased stimulus-induced somatosensory evoked potentials and CBF responses. Combined blockade of GABA-A and NMDA receptors yielded an additive decreasing effect $(-61 \%)$ of the evoked CBF compared with each antagonist alone, demonstrating cooperation of both excitatory and inhibitory systems in the hyperemic response. Blockade of prostanoid synthesis by inhibiting COX-2 (indomethacin, NS-398), expressed by 40\% of pyramidal cells but not by astrocytes, impaired the CBF response $(-50 \%)$. The hyperemic response was also reduced $(-40 \%)$ after inhibition of astroglial oxidative metabolism or epoxyeicosatrienoic acids synthesis. These results demonstrate that changes in pyramidal cell activity, sculpted by specific types of inhibitory GABA interneurons, drive the CBF response to whisker stimulation and, further, that metabolically active astrocytes are also required.

\section{Introduction}

The temporal and spatial coupling between increased neuronal activity and cerebral blood flow (CBF), known as neurovascular coupling, closely depends on incoming afferents and, primarily, their local processing by targeted neurons (Logothetis et al., 2001; Lauritzen and Gold, 2003; Angenstein et al., 2009). Additionally,

\footnotetext{
Received Sept. 20, 2010; revised April 29, 2011; accepted May 18, 2011

Author contributions: C.L., A.S., B.C., and E.H. designed research; C.L., A.K., P.F., and F.P. performed research; C.L., X.T., P.F., S.N., M.L., A.S., and E.H. analyzed data; C.L., A.S., B.C., and E.H. wrote the paper.

This work was supported by grants from the Canadian Institutes of Health Research (MOP-84209, E.H.; MOP102599 , A.S.), the Human Frontier Science Program (RGY0080/2008, A.S.; RGY0070/2007, B.C.), and the Centre National de la Recherche Scientifique ("Nitrex," B.C.), and by a Heart and Stroke Foundation of Canada/Canadian Stroke Network postdoctoral fellowship (C.L.). We thank Dr. E. Vaucher (Ecole d'optométrie, Université de Montréal, Montréal, Quebec, (anada) for access to laser Doppler facility in the early stage of this study, Dr. A. Silva (Laboratory of Functional and Molecular Imaging, NINDS, NIH) for allowing us to perform the pharmacological studies with cortical superfusion, M. A. Baig and Dr. S. Thomas (Brain Imaging Centre, Departments of Neurology and Neurosurgery and Biomedical Engineering, Montreal Neurological Institute, McGill University) for support in neurophysiological recordings, X.-K. Tong (Laboratory of Cerebrovascular Research, Montreal Neurological Institute, McGill University) and A. Karagiannis and P. Chausson (Laboratoire de Neurobiologie des Processus Adaptatifs, Université Pierre et Marie Curie, Paris) for help in astrocyte characterization, and C. Sandoe (Laboratory of Cerebrovascular Research, Montreal Neurological Institute, McGill University) for help with the c-Fos studies.

Correspondence should be addressed to Dr. Edith Hamel, Montreal Neurological Institute, McGill University, 3801 University Street, Montréal, Québec H3A 2B4, Canada. E-mail: edith.hamel@mcgill.ca.

*A. Kocharyan's present address: Laboratory of Functional and Molecular Imaging, NINDS, Bethesda, Maryland 20892.

DOI:10.1523/JNEUROSCI.4943-10.2011

Copyright $\odot 2011$ the authors $\quad 0270-6474 / 11 / 319836-12 \$ 15.00 / 0$
}

a coordinated interplay between neurons, astrocytes, and microvessels appears to be required for this highly regulated response that underlies contemporary brain imaging techniques that use vascular signals as surrogate markers of neuronal activity (Koehler et al., 2009; Carmignoto and Gómez-Gonzalo, 2010; Cauli and Hamel, 2010). Therefore, understanding the cellular basis of the activated neurocircuitry is essential for adequate interpretation of brain imaging data. A growing body of evidence suggests that both excitatory and inhibitory neurons govern the hemodynamic response to increased neuronal activity (Niessing et al., 2005; Kocharyan et al., 2008; Enager et al., 2009). However, the identity of the neurons recruited by a given afferent input, their interaction with astrocytes, and the mechanisms by which their activation results in changes in CBF remain largely unexplored.

The rodent whisker-to-barrel cortex pathway is a widely used model in the study of functional hyperemia (Woolsey et al., 1996; Jones et al., 2001). This sensory system allows rodents to acquire tactile information to build a map of their surroundings, information from each whisker being processed by distinct barrel structures in layer IV of the contralateral somatosensory cortex (Woolsey and Van der Loos, 1970; Ferezou et al., 2006). Neurons of the barrel cortex targeted by thalamocortical glutamatergic afferents have been extensively investigated anatomically and electrophysiologically (Staiger et al., 1996a,b; Maier and McCa- 

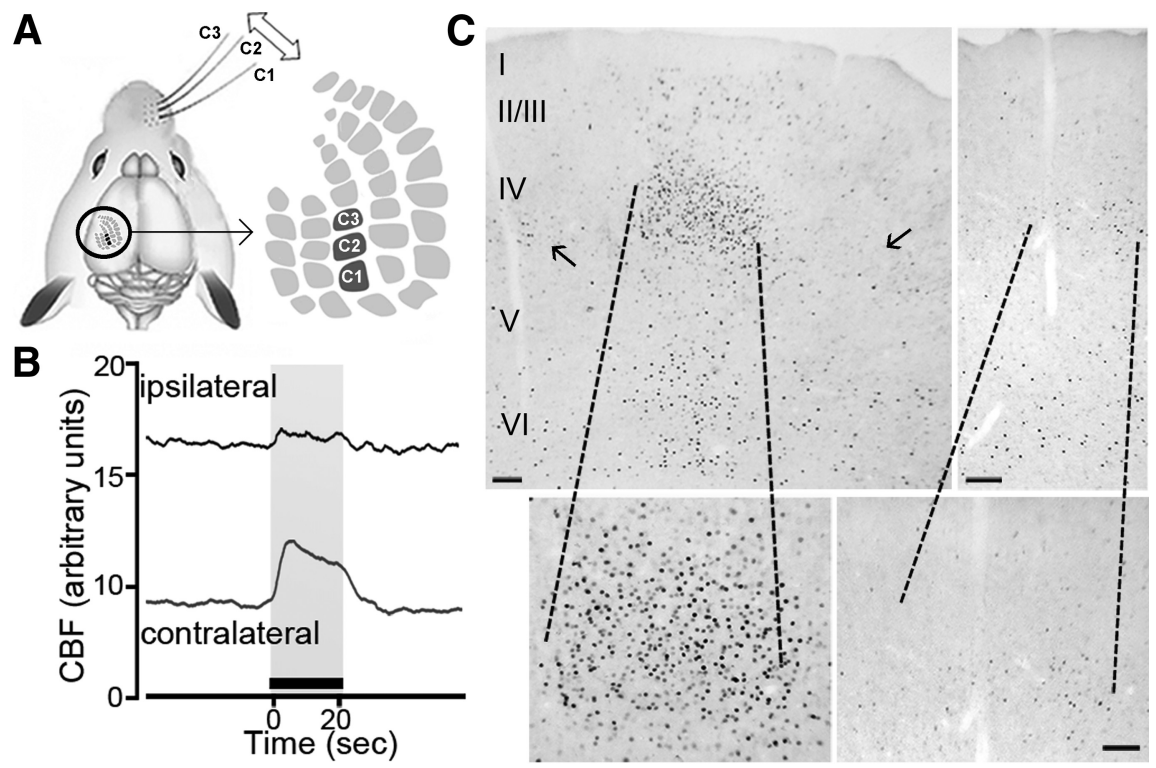

Figure 1. Increased CBF and C-Fos immunoreactivity induced by whisker stimulation. $\boldsymbol{A}$, Schematic representation of the stimulation paradigm of whiskers $\mathrm{C}_{1}, \mathrm{C}_{2}$, and $\mathrm{C} 3$ used for immunohistochemical studies and of the corresponding barrels in the somatosensory cortex (modified with permission from Aronoff and Petersen, 2008). $\boldsymbol{B}$, Representative cortical CBF recordings in the ipsilateral and contralateral cortices before and after whisker stimulation ( $20 \mathrm{~s}$, illustrated by the black bar above the $x$-axis) of all whiskers on the right snout. CBF was increased significantly only in the stimulated contralateral cortex, with a minimal response on the ipsilateral side $(n=3)$. C, Overall distribution of c-Fos immunostaining in a coronal section of the stimulated contralateral (left) and unstimulated ipsilateral (right) barrel cortices following 20 min whisker stimulation. Increased c-Fos-positive nuclei were selectively located in specific layers of the contralateral cortex and, particularly, in layer IV where the target barrel is located. Note that very few c-Fos-positive nuclei were present in adjacent neighboring barrels (small arrows in left panel). High magnifications of the barrels in both contralateral and ipsilateral cortices are shown at the bottom. Scale bar, $100 \mu \mathrm{m}$.

sland, 1997; Gentet et al., 2010). In addition to this highly organized neuronal connectivity, the blood supply of each barrel is also functionally compartmentalized (Cox et al., 1993). Following vibrissae stimulation, brain imaging studies have visualized local increases in $\mathrm{CBF}$ in the barrels corresponding to the stimulated whiskers (Martin et al., 2002; Dunn et al., 2005; Berwick et al., 2008). Given the robustness of this paradigm, it has been used to identify several mediators of the evoked CBF response (for review, see Koehler et al., 2009; Cauli and Hamel, 2010).

In the present study, we sought to identify the cortical excitatory and inhibitory neurons recruited in vivo by whisker stimulation, determine their respective contribution in the hemodynamic response, and assess whether astrocytes are involved in transmuting neuronal signals into vascular responses. Using double immunostaining for c-Fos as a reporter of neuronal activity (Staiger, 2006) and markers of excitatory and inhibitory neurons, together with in vivo pharmacology, we demonstrate that the evoked CBF response to whisker stimulation results from the recruitment of selective populations of excitatory pyramidal cells and inhibitory interneurons. Further, the data indicate that the vascular response is primarily driven by enhanced activity of output excitatory pyramidal neurons that release glutamate and cyclooxygenase-2 (COX-2) products. Moreover, metabolically active astrocytes and P450 epoxygenase vasoactive messengers are required for the full expression of this response.

\section{Materials and Methods}

Animals. Adult male Sprague-Dawley rats (280-320 g, Charles River) were used. Procedures were approved by the animal ethics committee of McGill University and followed the guidelines outlined by the Canadian Council on Animal Care. For slice experiments, young male Wistar rats (postnatal days $17 \pm 0.5$, Janvier) were used in accordance with the guidelines published in the European Communities Council Directive of November 24, 1986 (86/609/EEC).

Whisker stimulation. For anatomical studies, to prevent c-Fos induction related to stress and/or novelty (Staiger, 2006) rather than to the stimulus itself, rats were habituated to the stimulation protocol by a daily $\sim 30-45 \mathrm{~min}$ handling period for 1 week preceding the experimental day. During each session, rats were gently restrained in a plastic cone and the whiskers manually displaced with a paintbrush (3-4 Hz) (Filipkowski et al., 2000). Two days before the experiment, all but three whiskers $(\mathrm{C} 1, \mathrm{C} 2$, and $\mathrm{C} 3$ ) (Fig. 1A) on the right side and all whiskers on the left side of the snout were clipped close to the skin under sodium pentobarbital anesthesia $(60 \mathrm{mg} / \mathrm{kg}$, i.p.). On the experimental day, awake restrained rats were subjected to a $20 \mathrm{~min}$ stimulation of the right $\mathrm{C} 1-\mathrm{C} 3$ vibrissae, returned to their cages and killed $1 \mathrm{~h}$ later for brain fixation (see below). CBF measurement studies (detail below) were performed in urethane-anesthetized rats and, to avoid neuronal adaptation related to longlasting sensory stimulation (Heiss et al., 2008), a stimulus of higher frequency $(8-10 \mathrm{~Hz}$, electrical toothbrush) and shorter duration (3-6 stimulations of $20 \mathrm{~s}$ each interspaced by $40 \mathrm{~s}$ ) was used. The identity of the recruited cells under such conditions of stimulation and anesthesia was anatomically analyzed in a separate group of rats $(n=1-3)$ perfused after three stimulation blocks separated by $20 \mathrm{~min}$ intervals, saline being administered intracisternally before the second and third blocks to best mimic pharmacological experiments (see below).

Identification of activated cortical cells by double immunohistochemistry. Rats were anesthetized with pentobarbital and their brains perfusionfixed ( $500 \mathrm{ml}$ of ice-cold $4.0 \%$ paraformaldehyde in $0.1 \mathrm{M}$ phosphate buffer, $\mathrm{pH}$ 7.4). The cells recruited by whisker stimulation were identified by double immunohistochemistry of c-Fos and markers of pyramidal cells, specific subtypes of GABA interneurons or glial cells on free-floating freezing microtome $25 \mu \mathrm{m}$ thick coronal sections, as described previously (Kocharyan et al., 2008). Briefly, sections were first immunostained for c-Fos (rabbit anti-c-Fos, 1:15,000; Oncogene) detected with the ABC complex ( $45 \mathrm{~min}$, Vectastain ABC kit, Elite PK-6100, Vector Laboratories) and visualized with the SG reagent (SK-4700, Vector Laboratories, blue-gray precipitate). Whereas a few single-labeled c-Fos sections were kept aside to delineate the location of activated cells within the barrel cortex, most were processed for double immunostaining with all other antibodies detected in the second position with speciesspecific secondary antibodies (1:200, Vector Laboratories, $45 \mathrm{~min}$ ), and visualized with 3, 3'-diaminobenzidine (DAB, kit SK-4100, Vector Laboratories, brown precipitate). Primary antibodies were as follows: goat anti-choline acetyltransferase (ChAT, 1:250; Millipore Bioscience Research Reagents), anti-COX-1 or anti-COX-2 (1:500; Santa Cruz Biotechnology), guinea pig anti-VIP (1:5000; Peninsula), mouse antiparvalbumin (PV, 1:40,000; Sigma), or rabbit anti-GFAP (1:300; DAKO), anti-neuronal nitric oxide synthase (nNOS, 1:10,000; Millipore), or anti-somatostatin (SOM, 1:2000; Peninsula Laboratories). Sections were observed under light microscopy (Leitz Aristoplan, Leica), and digital pictures taken (CoolPix 4500, Nikon), calibrated, and edited with Adobe Photoshop 7 (Adobe Systems).

Laser Doppler flowmetry of CBF. Rats were anesthetized with urethane $(1.1 \mathrm{~g} / \mathrm{kg}$, i.p., in saline) and a catheter filled with heparinized saline inserted in the femoral artery for monitoring of physiological parameters. Animals were fixed in a stereotaxic frame (David Kopf Instruments), body temperature maintained at $37^{\circ} \mathrm{C}$ using a temperature control sys- 
tem (FHC), and the whiskers on the right side trimmed to a length of $\sim 1.0 \mathrm{~cm}$. The skull was exposed and a $3 \times 3 \mathrm{~mm}$ region over the left barrel cortex (bregma coordinates AP: $-3.0 \mathrm{~mm}$; L: $+/-7.0 \mathrm{~mm}$ ) (Gerrits et al., 1998) was thinned to translucency with a drill while being intermittently cooled with saline. CBF was recorded from a laser Doppler flowmetry (LDF) needle-shaped probe (Transonic Systems) positioned in areas free of large blood vessels before, during, and after stimulation. Pilot experiments $(n=3)$ with two laser probes on corresponding areas of the left and right barrel cortex showed the selectivity of the contralateral CBF response (Fig. 1B); therefore, all subsequent measures were performed only in the left barrel cortex. Pilot experiments demonstrated an evoked CBF response of comparable intensity whether induced with a toothbrush $(23.1 \pm 3.1 \%)$ or manually with a Q-tip $(19.1 \pm 1.9 \%, \sim 3-4$ $\mathrm{Hz}$, Niwa et al., 2000).

Pharmacology. To investigate the contribution of glutamatergic and GABAergic neurons, as well as of astrocytes in the evoked CBF response, pharmacological blockade of receptors, inhibition of vasoactive messenger synthesis, or astroglial metabolism was achieved by intracisternal injection (3 $\mu l$, i.c.) under microscope monitoring (Kocharyan et al., 2008). Antagonists targeted group I metabotropic glutamate receptors (mGluR-1 and mGluR-5, MPEP + LY367385, $n=5$ ), NMDA (MK-801, $n=8)$, GABA-A (picrotoxin, $n=7$ ), GABA-B (CGP 35348, $n=6$ ), muscarinic acetylcholine (mACh, scopolamine, $n=4)$, or VIP [VIP $(6-28), n=5$ ] receptors. Enzyme inhibitors targeted the rate-limiting prostanoid synthesizing enzymes COX (indomethacin, $n=3$ ), COX-1 (SC-560, $n=4$ ), and COX-2 (NS-398, $n=6$ ), the vasodilatory epoxyeicosatrienoic acids (EETs) synthetic enzymes P450 epoxygenases (MS-PPOH, $n=5$ ), and astroglial metabolism through inhibition of mitochondrial aconitase by the preferential uptake of fluoroacetate $(n=6)$ or fluorocitrate $(n=6)$ by glial cells (Fonnum et al., 1997). In each rat, only one compound or combination of two compounds was tested in addition to the no-drug and vehicle conditions. CBF measurements were recorded and averaged from three to six stimulations before and after either vehicle or drug administration (measured at 20,40, and $60 \mathrm{~min}$ after injection). Heart rate and arterial blood pressure (PowerLab, ADInstruments) as well as blood gases and pH (Rapid Lab 348, Bayer) were monitored throughout the experiment and were comparable between all conditions (supplemental Table 1, available at www.jneurosci.org).

Because it was recognized that simultaneous blockade of several pathways, even with high inhibitor or antagonist concentrations, did not fully inhibit the hyperemic response to sensory stimulation (Koehler et al., 2009; Leithner et al., 2010), we did not attempt to reach maximal inhibition but aimed to provide evidence for the contribution of specific pathways. Hence, we used a $10^{-4} \mathrm{M}$ concentration for most compounds except for fluoroacetate $\left(10^{-3} \mathrm{M}\right)$, fluorocitrate $\left(3 \times 10^{-4} \mathrm{M}\right)$, MK-801 $\left(4 \times 10^{-3} \mathrm{M}\right)$, and MSPP-OH $\left(10^{-3} \mathrm{M}\right)$, and presented the most efficacious incubation time for each compound. Concentrations and incubation times were determined from previous (Kocharyan et al., 2008) or from pilot studies based on demonstrated efficacy of the compounds after intracerebroventricular injection in other CNS-mediated functions. GABA receptor antagonists were used at doses that did not induce epileptic activity (Kocharyan et al., 2008; see below).

Drugs. Unless otherwise stated, drugs were prepared in $0.5 \mathrm{~m}$ PBS. MK-801, CGP35348, and picrotoxin (vehicle $0.5 \%$ ethanol in $0.5 \mathrm{M}$ PBS) were purchased from Tocris Bioscience. Fluoroacetate sodium, fluorocitrate, indomethacin (vehicle $0.2 \%$ ethanol in $0.5 \mathrm{M}$ PBS), MPEP, LY-367385 (vehicle $10^{-3} \mathrm{M} \mathrm{NaOH}$ in $0.5 \mathrm{M}$ PBS equilibrated to $\mathrm{pH} 7.4$ with $1 \mathrm{~N}$ $\mathrm{HCl})$, scopolamine, and VIP(6-28) were from Sigma. MS-PPOH $[\mathrm{N}-$ (methylsulfonyl)-2-(2-propynyloxy)-benzenehexanamide, vehicle $0.5 \%$ ethanol in $0.5 \mathrm{M} \mathrm{PBS}$, NS-398 ( $N$-[2-(cyclohexyloxy)-4-nitrophenyl]methanesulfonamide, vehicle 1.5\% DMSO in 0.5 M PBS) and SC-560 [5-(4chlorophenyl)-1-(4-methoxyphenyl)-3-(trifluoromethyl)-1H-pyrazole, vehicle $0.5 \%$ ethanol in $0.5 \mathrm{M}$ PBS] were obtained from Cayman Chemicals.

Electrophysiological recordings. This approach was used to measure the concurrent effects of picrotoxin on somatosensory evoked potentials (SEP) and CBF. Rats were prepared as indicated above for pharmacological studies with the following modifications. The bone over the somatosensory cortex was removed to expose the dura mater. A chamber made of silicone was created on top of the surrounding bone, filled with saline, and a 16-channel electrocorticography (ECoG) array specifically designed for the rat barrel cortex (NeuroNexus Technologies) was positioned. The LDF probe was positioned above the array and, once a reproducible stimulus-evoked CBF response was detected, the positions of the array and the LDF probe were secured with $1 \%$ agar. Whiskers were deflected $(4 \mathrm{~Hz})$ using an air-puff stimulator (Sanganahalli et al., 2008) during 10 stimulation blocks (20 s on interspaced by $40 \mathrm{~s}$ off) following intracerebroventricular injection $(3 \mu \mathrm{l})$ of either vehicle or picrotoxin $\left(10^{-4} \mathrm{M}\right)$, with a $20 \mathrm{~min}$ interval between the two conditions. Electrophysiological data were acquired at $24 \mathrm{kHz}$ using a RZ2 multichannel recording system (Tucker-Davis Technologies) and analyzed using analysis scripts written in MATLAB (MathWorks). SEP data were obtained after resampling at $2 \mathrm{kHz}$ and filtering between 0.5 and $250 \mathrm{~Hz}$. SEP amplitudes were measured by averaging twenty $1 \mathrm{~s}$ epochs within each stimulation block and identifying the four pairs of trough (P deflection) and peak ( $\mathrm{N}$ deflection) associated with the $4 \mathrm{~Hz}$ stimulation. The average trough-to-peak amplitude was then computed for each of the 10 stimulation blocks, in each of the 16 channels of the ECoG array. The 10 resulting SEP amplitudes (1 per each stimulation block) were used to identify channels that demonstrated statistically significant SEP after vehicle injection (one-tailed $t$ test, comparison between trough-to-peak amplitudes during stimulation epochs and corresponding times during the baseline epochs). In one rat, six of the channels did not show statistically significant SEP and were therefore excluded from the analysis. The SEP amplitudes were averaged over ECoG contacts to obtain the overall SEP amplitudes under vehicle or picrotoxin injection.

Closed cranial window testing. This approach was used to compare the vascular effect of picrotoxin after cortical superfusion with that observed after intracerebroventricular injection and to measure picrotoxin effects on EEG activity. Rats were anesthetized with isoflurane (5\% in 30\% oxygen for induction, $2-2.5 \%$ for maintenance) and placed under artificial ventilation via tracheotomy (50 bpm, SAR 830/P ventilator, CWE). Respiratory parameters, including tidal pressure, $\mathrm{O}_{2}$ saturation, and endtidal $\mathrm{CO}_{2}$ levels, were monitored via a capnograph (BCI 300 Capnocheck, $\mathrm{BCI})$, and rectal temperature was kept stable with a heating blanket $\left(\sim 37^{\circ} \mathrm{C}\right.$, TC-1000 temperature controller, CWE). The femoral artery and vein were cannulated for arterial blood pressure recordings and blood analysis ( $\mathrm{pH}, \mathrm{pCO} 2$, and pO2, ABL 80 FLEX, Radiometer) and pancuronium bromide infusion $(0.5 \mathrm{mg} / \mathrm{kg} / \mathrm{h})$, respectively. Rats were then placed in a stereotaxic frame, the bone and dura overlying the right barrel cortex (coordinates as above) were removed ( $\sim 2 \mathrm{~mm}$ diameter), and the exposed cortex was covered with $1 \%$ agarose in artificial CSF (aCSF) (Harvard Apparatus). A piece of standard \#1 glass coverslip was sealed over this region with dental cement, through which three tubes were placed for aCSF circulation, vehicle or picrotoxin $\left(10^{-6} \mathrm{M}\right)$ superfusion ( $5 \mu \mathrm{l} / \mathrm{min}, 0-30 \mathrm{~min}$ ), or insertion of the EEG recording electrode. Two reference electrodes were placed on the thinned skull on the contralateral side and over the cerebellum. Anesthesia was then switched to urethane ( $1 \mathrm{~g} / \mathrm{kg}$, i.p., 2 injections over $30 \mathrm{~min})$ and, after recovery (30 $\mathrm{min})$, the CBF responses to left whisker stimulation were measured by laser Doppler (Moor Instruments) using a probe positioned on the coverslip. EEG potentials were amplified 10,000-fold, digitized at a sampling rate of $2.0 \mathrm{kHz}$, transferred to a computer, and analyzed off-line using scripts written in MATLAB between $(0-30 \mathrm{~Hz})$ under aCSF, vehicle, and picrotoxin and presented as spectrum analysis (Lévesque et al., 2009). Physiological parameters were unaltered (supplemental Table 1, available at www.jneurosci.org).

Whole-cell recordings and single-cell RT-PCR. Young rats were decapitated, their brains quickly removed, and coronal slices (300 $\mu \mathrm{m}$ thick) containing the barrel cortex were cut using a vibratome (Karagiannis et al., 2009). Individual slices were transferred to a recording chamber and perfused $(1-2 \mathrm{ml} / \mathrm{min})$ with oxygenated aCSF $\left(30-34^{\circ} \mathrm{C}\right)$. Patch pipettes (4-8 M $\Omega$ ) were filled with $8 \mu \mathrm{l}$ of autoclaved K-gluconate-based RTPCR internal solution. Astrocytes and pyramidal neurons were visualized in the slice using infrared videomicroscopy with Dodt gradient contrast optics, and astrocytes were also stained by superfusion (20 min) of aCSF containing $1 \mu \mathrm{M}$ sulforhodamine 101 hydrate (SR101, Sigma) (Nimmerjahn et al., 2004). SR101 was excited at $535 \mathrm{~nm}$ with a light-emitting diode system (CoolLED, Precise Excite) and red fluorescence collected at 
Table 1. PCR primers used in the RT-PCR protocol for astrocytes and pyramidal cells

\begin{tabular}{|c|c|c|c|c|}
\hline Gene accession \# & First $P C R$ primers & Size (bp) & Second PCR nested primers & Size (bp) \\
\hline GFAP & Sense, 454 AGCTCCAAGATGAAACCAACCT ${ }^{a}$ & 631 & Sense, 509 ACAGACAGGAGGGGGATGAA & 263 \\
\hline NM_017009 & Antisense, 1066 CGATCTCGATGTCCAGGG ${ }^{a}$ & & Antisense, 749 GGACCGATACCACTCTTCTGTTT & \\
\hline$S 100 \beta$ & Sense, 45 CATCAGTATTCAGGGAGAGAGGG & 166 & Sense, 58 GGGAGAGAGGGTGACAAGCA & 132 \\
\hline COX-1 & Sense, 27 GTTTCCCCTGCTGCTGCTC & 359 & Sense, 137 AGGGTGTCTGTGTCCGCTTC & 185 \\
\hline NM_017043.1 & Antisense, 366 GGCTGGGGATAAGGTTGGAC & & Antisense, 301 GGCATTCACAAACTCCCAGAT & \\
\hline $\operatorname{cox}-2$ & Sense, 199 CTGAAGCCCACCCCAAACAC & 247 & Sense, 202 AAGCCCACCCCAAACACAGT & 206 \\
\hline NM_053859.1 & Antisense, 600 CCAGCCGACTCCGTTCTAAG $^{b}$ & & Antisense, 553 ATGGCAAGCAGGGTATGTGAC ${ }^{b}$ & \\
\hline
\end{tabular}

Position 1, first base of the start codon.

aLambolez et al., 1992.

${ }^{b}$ Gallopin et al., 2006.

607/34 nm using a bandpass filter (Semrock). Images were captured with a digital camera (CoolSnap HQ2, Roper Scientific) and Imaging workbench 6.0 software (Indec). Whole-cell electrophysiological properties were recorded in voltage clamp mode for astrocytes and in current clamp mode for pyramidal neurons. Input resistance of astrocytes was determined by plotting a voltage/current curve of the current response at steady state and was corrected for series resistance determined by plotting a voltage/current curve of the capacitive transients. Input resistance of pyramidal neurons was measured as described previously (Karagiannis et al., 2009). Membrane potential values were not corrected for liquid junction potential. At the end of the recording, the cell cytoplasm was aspirated in the recording pipette, expelled into a test tube, and reverse transcription (RT) performed (Lambolez et al., 1992). Two single-cell RT-PCR (scRT-PCR) protocols were designed to detect the expression of COX-1 and COX-2 isoforms simultaneously with GFAP and the calcium-binding protein $(\mathrm{S} 100 \beta)$ in astrocytes or with the vesicular glutamate transporter 1 (VGlut1) in pyramidal cells. Two amplification steps were performed essentially as described (Cauli et al., 1997), with 10 $\mu l$ of the RT reaction products using the primer pairs listed in Table 1.

Statistical analysis. For immunohistochemistry, one to three sections per rat were taken at the bregma levels corresponding to the somatosensory cortex. Cells costained for both c-Fos and the selected markers were counted in layers II-IV under the microscope in both the c-Fosdelineated activated contralateral barrel and the corresponding, nonstimulated area in the ipsilateral cortex. Counts were expressed as a percentage of the total population of labeled cells counted for each cell type. The total number of cells counted was 1073 (COX-2), 279 (VIP), 205 (ChAT), 424 (SOM), 282 (nNOS), and 268 (PV) for the long stimulation in awake rats ( $n=4-6$ rats). For the short duration stimulus under urethane anesthesia, the counted cells corresponded to 552 (COX2), 161 (VIP) 164 (SOM), 104 (nNOS), and 87 (PV) ( $n=1-3$ rats). Double-labeled cells in the ipsilateral and contralateral sides were compared by Student's $t$ test and data expressed as specifically activated cells after subtracting the percentage activation on the ipsilateral side from the contralateral side.

CBF changes induced by whisker stimulation were measured in arbitrary flux units, saved, and analyzed on a PC using Chart 7 software (ADInstruments). The percentage changes were averaged over the $20 \mathrm{~s}$ period of whisker stimulation obtained from five or six trials. Drug effects were tested by repeated-measures ANOVA and a post hoc NewmanKeuls test. Changes in SEP amplitude and evoked CBF responses between vehicle and picrotoxin were compared by paired Student's $t$ test, and data were correlated using a Pearson correlation.

Comparison of the occurrence of COX-1 and COX-2 between recorded astrocytes and pyramidal neurons was done according to:

$$
|\varepsilon|=\frac{\left|p_{\mathrm{a}}-p_{\mathrm{b}}\right|}{\sqrt{\frac{p q}{n_{\mathrm{a}}}+\frac{p q}{n_{\mathrm{b}}}}}
$$

where $p_{\mathrm{a}}$ and $p_{\mathrm{b}}$ represent the percentage of occurrence, and $n_{\mathrm{a}}$ and $n_{\mathrm{b}}$ represent the number of individuals in populations $a$ and $b$. The variable $p$ denotes the percentage of occurrence in the overall population with $q=$ $1-p$. The quantity $|\varepsilon|$ was tested against a normal distribution to determine statistical significance of the difference of expression (Fisher and Yates, 1963). Comparison of electrophysiological and morphological properties between populations was performed using a Mann-Whitney $U$ test.

All reported values are means \pm SEM. All statistical analyses were performed with Prism4 (GraphPad Software), and $p<0.05$ was considered significant.

\section{Results}

Contralateral barrel cortex activation by vibrissal stimulation Baseline $\mathrm{CBF}$ recorded in the barrel cortex was very stable, and deflection of the right facial vibrissae resulted in a sharp increase in CBF on the contralateral side $(23.1 \pm 3.1 \%)$, with a much smaller response on the ipsilateral cortex $(1.8 \pm 0.4 \%, n=3, p<$ 0.05 ) (Fig. $1 B$ ). Because the BOLD response in the whisker-tobarrel pathway is paralleled by the strength of c-Fos expression in the respective cortical layers ( $\mathrm{Lu}$ et al., 2004), we used c-Fos upregulation as an index of the neuronal activation underlying hemodynamic changes. As expected, the selective increase in contralateral $\mathrm{CBF}$ was substantiated by increased c-Fos induction in the contralateral barrel cortex following $\mathrm{C} 1-\mathrm{C} 3$ whisker stimulation. The c-Fos immunoreactivity was prominent in layer IV, but also occurred in layers II/III and V/VI (Fig. 1C). The barrelrelated columnar organization corresponding to the stimulated whiskers was clearly delineated. In contrast, there were few c-Fos immunolabeled cells in the ipsilateral barrel cortex and in the neighboring barrels where spreading subthreshold depolarizations have been reported (Ferezou et al., 2006) (Fig. 1C). This is explained by the fact that depolarizations in the areas surrounding the recruited barrels are presumably unable to induce sufficient synchronized action potentials (Petersen et al., 2003; Ferezou et al., 2006) required for c-Fos induction (see Discussion). We then determined the neurochemical identity of recruited neuronal populations in layers II-IV that are encompassed in the CBF readings measured with laser Doppler.

\section{Recruitment of specific subsets of pyramidal cells and GABA interneurons}

Double-immunostained sections revealed recruitment of pyramidal cells immunostained for COX-2, which is constitutively expressed in a subgroup of these neurons in the cerebral cortex (Yamagata et al., 1993; Breder et al., 1995). These doubleimmunostained c-Fos/COX-2 pyramidal cells were mainly located in layers II/III (Fig. $2 \mathrm{~A}$ ), but were also intermingled within the activated layer IV of the barrel (15\% of all COX-2 cells being specifically c-Fos-positive) (Fig. $2 \mathrm{~B}, \mathrm{H}$ ). Several GABA interneu- 
rons, primarily in layers II/III and in the outer rim of the layer IV barrel, were also recruited by whisker stimulation. They corresponded to those that coexpressed VIP or ChAT in which c-Fos-positive nuclei were essentially observed $(24 \%$ and $19 \%$ of VIP and ChAT interneurons, respectively) (Fig. 2D,E,H). In contrast, PV-, SOM-, or NOS-expressing GABA interneurons did not show significantly increased c-Fos immunostaining compared with the nonstimulated side (Fig. $2 \mathrm{~F}-\mathrm{H}$ ). Double immunostaining for COX-1, which mainly labeled microglial cells (Deininger and Schluesener, 1999; Yermakova et al., 1999), revealed no colocalization with c-Fos (Fig. 2C). This excluded c-Fos as a marker of recruited microglial cells under sensory stimulation, as shown before for astrocytes (Staiger et al., 2002) and confirmed here by the lack of GFAP/ c-Fos double-labeled astrocytes (data not shown).

To further address the cellular distribution of COX isoenzymes, in view of our anatomical results above and the controversy on the role of COX-1-derived prostanoids in the neurovascular coupling response to sensory stimulation (Niwa et al., 2001; Takano et al., 2006, Gordon et al., 2008), we performed scRT-PCR experiments in identified layer II/III pyramidal neurons and astrocytes. We confirmed COX-2 mRNA expression in a subset of recorded pyramidal neurons $(40 \%, n=20)$, and also detected COX-1 mRNA in these cells (50\%) (Figs. 3A-C), a finding likely reflecting their very low level of COX-1 protein, as noted recently (Tanaka et al., 2009). In contrast,

COX-1 or COX-2 mRNAs were detected in few $(10 \%)$ or none $(0 \%)$ of the recorded SR101-labeled astrocytes $(n=20, p<0.01)$, whose identity was confirmed by their significantly lower input resistance $(66 \pm 14 \mathrm{M} \Omega$ vs $183 \pm 15 \mathrm{M} \Omega$ for pyramids, $p<0.001)$ and more hyperpolarized resting membrane potential $(-86.9 \pm 1.6 \mathrm{mV}$ vs $-66.1 \pm 1.9 \mathrm{mV}$ for pyramids, $p<0.001$ ), lack of action potential, linear I/V relationship (Kafitz et al., 2008), and expression of astroglial marker $\mathrm{S} 100 \beta$ and GFAP (Fig. 3D-F). Although cortical astrocytes in the early developing cerebral cortex transiently express COX-2 (Cahoy et al., 2008), our scRT-PCR data obtained from juvenile rats corresponded to the adult phenotype as indicated by their electrophysiological properties (Houades et al., 2008; Kafitz et al., 2008) and the absence of COX-2 expression both at the mRNA (Cahoy et al., 2008) and protein (Takano et al., 2006; this study) levels.

\section{Mediators of the hemodynamic response to vibrissal stimulation}

When recruited neurons were identified in urethaneanesthetized rats submitted to a short-duration whisker stimulation, as used for pharmacological experiments, c-Fos immunostaining was of a weaker intensity compared with that in awake rats. However, COX-2 (23\%) and VIP (20\%) neurons were also selectively recruited on the activated side, whereas SOM (3\%), NOS
( $2 \%$ ), and PV ( $0 \%$ ) positive GABA interneurons were not, allowing use of these experimental conditions in the pharmacological dissection of the hyperemic response.

\section{Implication of COX-2 pyramidal cells and glutamatergic} neurotransmission

As c-Fos was induced in a significant proportion of COX-2 pyramidal cells (Fig. $2 B, H$ ), we first investigated the contribution of prostanoids in the hyperemic response. Blockade of their synthesis by nonselective COX inhibition (indomethacin) or selective inhibition of COX-2 (NS-398), but not COX-1 (SC-560), lessened the CBF response to whisker stimulation, with decreases corresponding to $51.2 \pm 12.0 \%(p<0.05), 51.2 \pm 8.0 \%(p<$ 0.01 ), and $5.2 \pm 2.2 \%$ (n.s., up to $60 \mathrm{~min}$ ), respectively (Fig. $4 A, B)$. These findings unequivocally confirmed the implication of COX-2 products in this hyperemic response, as originally reported in the mouse (Niwa et al., 2000). Together with the lack of COX-2 expression in astrocytes at the mRNA (Fig. 3D-F) and protein (Fig. $2 A, B$ ) (Takano et al., 2006) levels and c-Fos protein induction in COX-2 pyramidal cells (Fig. $2 B, H$ ), these observations demonstrate that COX-2 pyramidal neurons are the primary source of dilatory COX-2-derived prostanoids in the hyperemic response to whisker stimulation.

A role for NMDA receptors has previously been reported in the evoked CBF response or generation of the BOLD signal after 

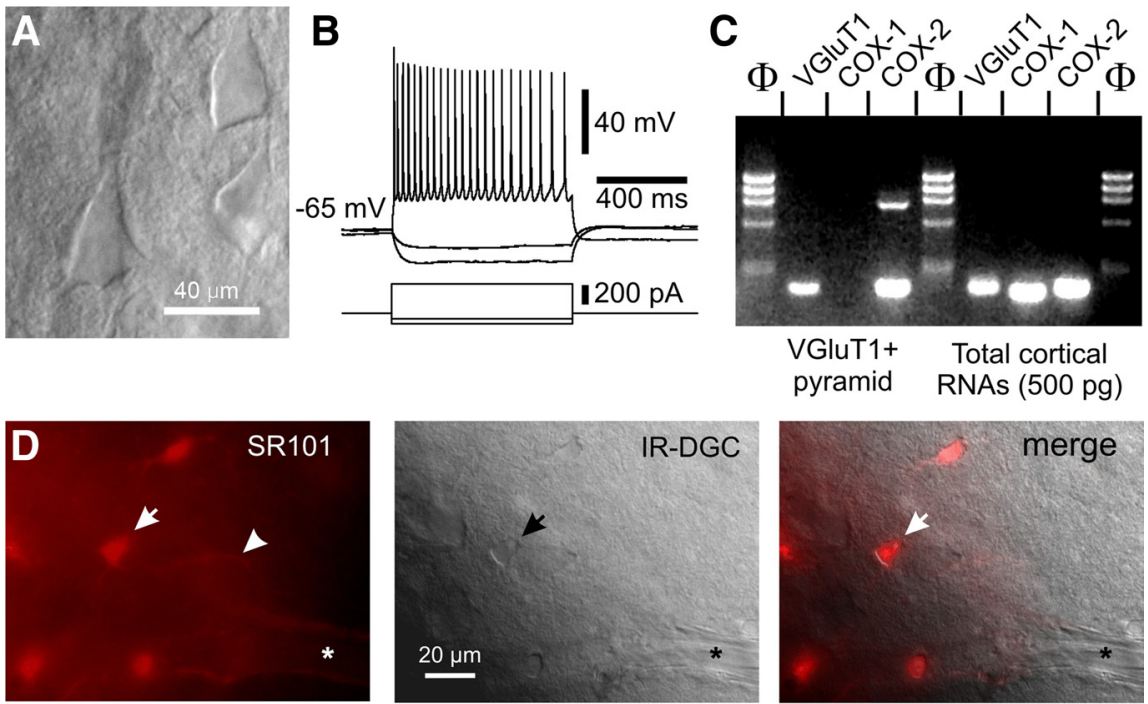

E

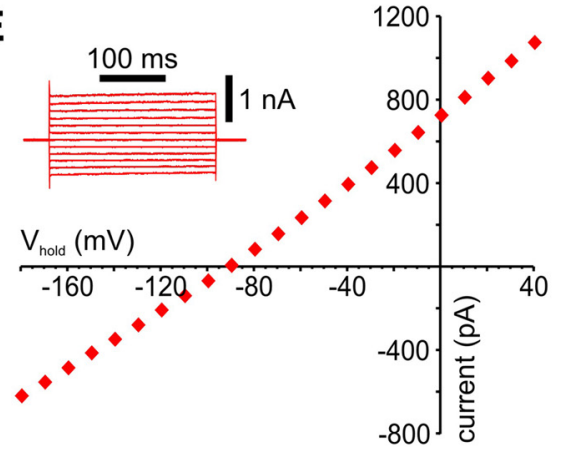

$\mathbf{F}$

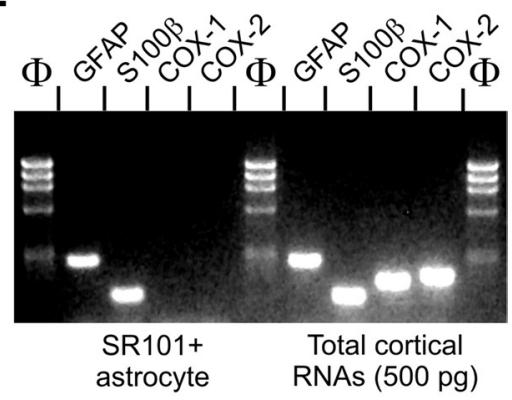

Figure 3. Electrophysiological and molecular analyses of pyramids and perivascular astrocytes. $A$, Infrared Dodt gradient contrast (IR-DGC) image of a layer III pyramidal cell that showed the typical firing of a regular spiking neuron with frequency adaptation and amplitude accommodation of action potentials in current clamp recordings $(\boldsymbol{B})$. $\boldsymbol{C}$, This pyramidal cell also expressed VGluT1 and COX-2; the high molecular weight band in the COX-2 lane corresponds to genomic amplification. RT-mPCR protocol performed on $500 \mathrm{pg}$ of total cortical RNAs showing PCR products corresponding to the expect sizes for VGluT1, COX-1, and COX-2 amplicons. D, SR101 vital staining of perivascular cortical astrocytes. Wide-field fluorescence imaging of a SR101-labeled cortical slice (left panel) showing an intensely labeled astrocyte (arrow) and its process (arrowhead) in the vicinity of a diving arteriole $\left({ }^{*}\right)$. The pial surface is on the right side. Corresponding field under IR-DGC (middle panel); superimposition of the two images is shown in the right panel. The arrow indicates the SR101-stained astrocyte that was recorded in whole-cell configuration depicted in $\boldsymbol{E}$. Note the linear I/V curve and the hyperpolarized resting membrane potential characteristic of passive astrocytes. The inset illustrates representative current responses evoked by voltage steps (from $-180 \mathrm{mV}$ to $+40 \mathrm{mV}, 20 \mathrm{mV}$ increments) used to determine the I/V curve at steady state. $\boldsymbol{F}, \mathrm{RT}-\mathrm{mPCR}$ analysis of the SR101-positive astrocyte (shown in $\boldsymbol{A}$ and $\boldsymbol{B}$ ) revealed expression of GFAP and $\mathrm{S} 100 \beta$, but not COX-1 or COX-2, whereas total cortical RNAs showed PCR products of the expect size for all amplicons. Lanes $\Phi$ correspond to the molecular weight marker Phi X 174/Haell.

sensory stimulation (Norup Nielsen and Lauritzen, 2001; Gsell et al., 2006). Additionally, activation of NMDA receptors was shown to stimulate the neuronal release of COX-2-derived prostaglandin E2 ( $\left.\mathrm{PGE}_{2}\right)$ (Pepicelli et al., 2005), a major vasodilator prostanoid. We therefore evaluated the contribution of NMDA receptors and found that their antagonism with MK-801 decreased the evoked CBF response $(-37.3 \pm 8.6 \%, p<0.01)$ (Fig. $5 A$ ). Further, as expected from a sequential process involving activation of NMDA receptors and subsequent release of COX-2 derived prostanoids, combined NMDA receptor and COX-2 blockade did not potentiate the inhibition seen with either compound alone, and the reduction was almost identical to that induced by MK-801 alone $(-39.0 \pm 3.6 \%, p<0.001)$ (Fig. $5 B)$. We then assessed the implication of group I mGluRs, identified as a required signaling cascade in the hyperemic response to sensory stimulation (Zonta et al., 2003; Shi et al., 2008). We found that combined blockade of mGluR1, restricted to a subset of cortical
GABA interneurons (Baude et al., 1993) including those that contain VIP (Cauli et al., 2000) and mGluR5 that are expressed in most cortical neurons and astrocytes (Cauli et al., 2000; Cahoy et al., 2008), with MPEP and LY367385 significantly reduced the evoked $\mathrm{CBF}$ response $(-40.3 \pm 5.3 \%, p<0.01)$ (Fig. $4 C)$. Together, these data emphasize the multifaceted sites of action for glutamate in this hemodynamic response.

\section{Implication of inhibitory $G A B A$ interneurons}

As whisker stimulation induced c-Fos in GABA interneurons that selectively expressed VIP and ACh, we then evaluated the implication of these established vasoactive mediators in the evoked CBF response. Surprisingly, blockade of vasodilatory $\mathrm{mAChR}$ or VIP receptors using antagonists [scopolamine or $\operatorname{VIP}(6-28)$ ] with reported efficacy on stimulusevoked CBF responses (Nakao et al., 1999; Kocharyan et al., 2008) or other CNS functions (Gajewska et al., 2005) did not affect this hyperemic response, even after 40 or 60 min (Fig. 4C). Similarly, blockade of GABA-B receptors with CGP35348 (tested up to $10^{-2} \mathrm{M}$ ) failed to alter the CBF response (Fig. $4 C$, for $10^{-4} \mathrm{M}$ ). In contrast, blockade of GABA-A receptors with picrotoxin administered by intracisternal injection (Fig. 6A) or cortical superfusion through a cranial window (Fig. $4 C)$ significantly decreased the evoked $\mathrm{CBF}$ response compared with vehicle $(-30.6 \pm 7.2 \%, p<0.05$, or $-36.6 \pm$ $4.6 \%, p<0.05$, at $20 \mathrm{~min}$ ). This occurred without any effect of picrotoxin on baseline CBF or global cortical activity, as shown by cortical EEG recordings (Fig. $6 B$ ), in accordance with our previous findings after intracisternal injection (Kocharyan et al., 2008). A more refined analysis of SEP within the activated barrel cortex showed a significant correlation between the effects of picrotoxin on the sensory-evoked CBF response and on the SEP amplitude $(p<0.01, n=12)$ (Fig. $7 A-C)$. When all rats were taken in the analysis, including two that did not respond to picrotoxin based on no change in their evoked CBF response, the decrease in the SEP amplitude under picrotoxin compared with vehicle nearly reached significance $(p=0.065)$ (Fig. $7 B)$. However, when analysis was performed only in rats with decreased CBF responses $(n=10$ of 12$)$, the latter taken as a criterion for effective intracisternal picrotoxin injection, a significant decrease in the SEP amplitude following picrotoxin administration was evidenced $(p<0.05)$ (Fig. $7 D$ ). Together, these data indicate that GABA, but not ACh or VIP, presumably released from recruited interneurons and acting via GABA-A receptors is involved in the hyperemic response. The data further indicate a key role for GABA in balancing excitation and orchestrating action potential in excitatory neurons (Cardin 
et al., 2009; Gentet et al., 2010). Moreover, the correlation between the changes in SEP and evoked CBF responses induced by picrotoxin indicates that the decreased CBF responses are linked to decreased synchronized neuronal responses. Yet, a small effect of picrotoxin on cerebrovascular GABA-A receptors cannot be totally excluded because no change in SEP was associated with a $9.4 \%$ decrease in the hyperemic response (Fig. $6 C$, intercept). It should be noted, however, that subtle changes in inhibitory microcircuits do not necessarily cause significant changes in global cortical activity.

\section{Independent contribution of excitatory and inhibitory neurons}

To evaluate the relative contribution of glutamatergic and GABAergic transmission, we combined injection of picrotoxin and MK-801, which yielded a significantly higher inhibition of the CBF response $(-61.1 \pm 7.4 \%, p<0.001)$ as compared with either compound alone ( $p<0.05$ vs either MK-801 or picrotoxin) (Figs. 4C, 6C). These observations pointed to NMDA and GABA-A receptors contributing to the evoked CBF response, at least partly through distinct pathways, notwithstanding the glutamate effects mediated through receptors other than NMDA, such as mGluRs and AMPA/kainate receptors (Norup Nielsen and Lauritzen, 2001; Zonta et al., 2003; Lovick et al., 2005; Gsell et al., 2006; Shi et al., 2008; this study). We similarly combined COX-2 inhibition and GABA-A receptor blockade, but this failed to further impair the hyperemic response compared with COX-2 inhibition alone $(-51.9 \pm$ $9.4 \%$ vs $-51.2 \pm 8.0 \%$ ) (Figs. $4 B, 6 D$ ). This finding, rather than resulting from a serial process involving GABA-A receptors activation and release of COX-2-derived prostanoids, as is the case for NMDA receptors, may reflect the reported decreasing effects of COX-2 inhibition on neurotransmission (Slanina and Schweitzer, 2005) and, therefore, neurovascular coupling.

Astroglial messengers as intermediaries for both inhibitory and excitatory neurons Although sensory input recruits cortical astrocytes (X. Wang et al., 2006), their activation cannot be probed by c-Fos induction (Staiger et al., 2002; this study). Consequently, we first explored their implication as cellular intermediary in neurovascular coupling (Carmignoto and Gómez-Gonzalo, 2010) by impairing their oxidative metabolism with fluorocitrate and fluoroacetate, which are preferentially taken up by astrocytes compared with neurons (Fonnum et al., 1997; Lian
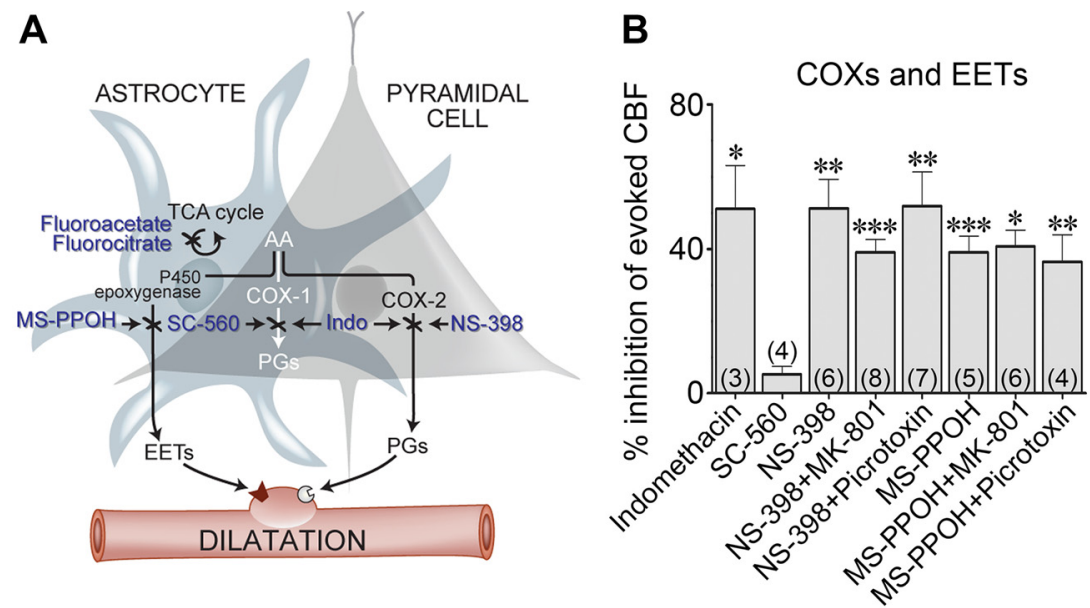

C

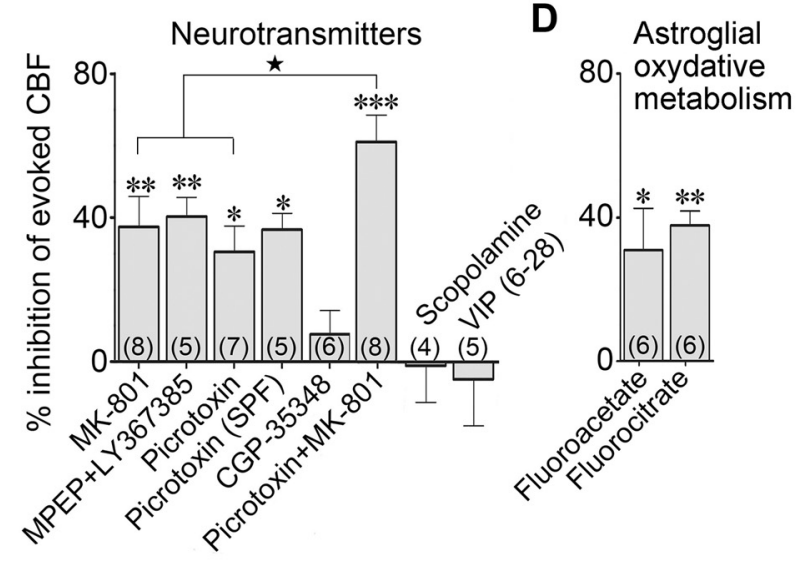

Figure 4. Blockade of specific neurotransmitter receptors, synthesis of dilatory mediators, or astroglial metabolism impaired the CBF response evoked by whisker stimulation. $\boldsymbol{A}$, Neuronal and astroglial pathways and sites of action (indicated by $X$ ) of the different pharmacological tools used. The shaded area indicates that the COX-1 pathway is common to both astrocytes and pyramidal neurons, whereas the P450 epoxygenase and COX-2 pathways are located in astrocytes and neurons, respectively. AA, Arachidonic acid; Indo, indomethacin; PGs, prostaglandins; TCA, tricarboxylic acid. $\boldsymbol{B}$, Whisker stimulation-evoked CBF responses were reduced after nonselective COX inhibition (indomethacin), an effect mimicked by COX-2 (NS-308), but not COX-1 (SC-560), inhibition. Combined administration of MK-801 and NS-398 did not further inhibit the evoked CBF response. Similarly, combined blockade of COX-2 (NS-398) and NMDA (MK-801) or GABA-A (picrotoxin) receptors did not have a larger effect than NS-398 alone. The evoked CBF response was reduced by inhibition of EET synthesis (MS-PPOH), an effect not potentiated when combined with blockade of NMDA or GABA-A receptors. C, Evoked CBF responses were reduced after antagonism of NMDA receptors with MK-801, of group I mGluRs with MPEP and LY367385, and GABA-A receptors with picrotoxin [either after intracisternal injection or superfusion through a closed cranial window (SPF)]. In contrast, blockade of GABA-B (CGP35348), muscarinic ACh (scopolamine), or VIP [VIP(6-28)] receptors did not alter the evoked CBF response. Combined GABA-A and NMDA receptor blockade with picrotoxin and MK-801 had an additive reducing effect on the evoked (BF when compared with each compound individually. D, Whisker stimulation-evoked (BF increases were reduced after inhibition of astroglial oxidative metabolism (fluorocitrate, fluoroacetate). The number of rats used is indicated within parentheses. Values are mean \pm SEM of change versus the evoked CBF response after vehicle injection. ${ }^{*} p<0.05,{ }^{* *} p<0.01,{ }^{* * *} p<0.001$ versus vehicle by repeated-measures ANOVA. $\star p<0.05$ versus MK-801 or picrotoxin alone, by one-way ANOVA.
A

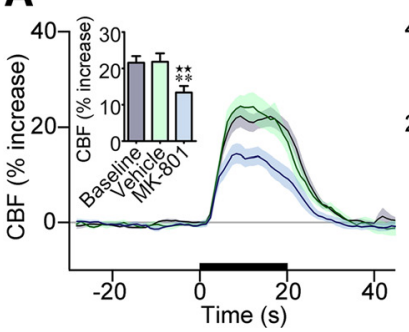

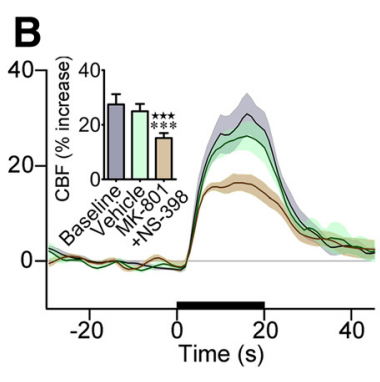

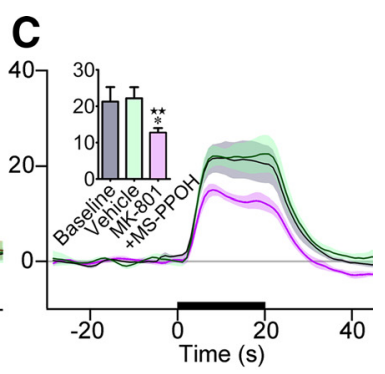

Figure 5. NMDA receptor blockade reduced the CBF response to whisker stimulation. $A$, Average CBF responses to whisker stimulation at baseline, following vehicle or NMDA receptor antagonism with MK-801. MK-801 significantly decreased the evoked CBF responses ( $n=$ 8). There was no additive effect when NMDA receptors were blocked concurrently with inhibition of COX-2 with NS-398 (B, $n=8)$ or P450 epoxygenase with MS-PPOH $(\boldsymbol{C}, n=5)$. None of the vehicles had an effect on baseline or evoked CBF. The 20 s stimulation is indicated by the black line on the $x$-axis, and shaded areas denote SEM. Values are mean \pm SEM. $\star \star p<0.01, \star \star \star p<0.001$ versus baseline. ${ }^{*} p<$ $0.05,{ }^{* *} p<0.01,{ }^{* * *} p<0.001$ versus vehicle by repeated-measures ANOVA. 

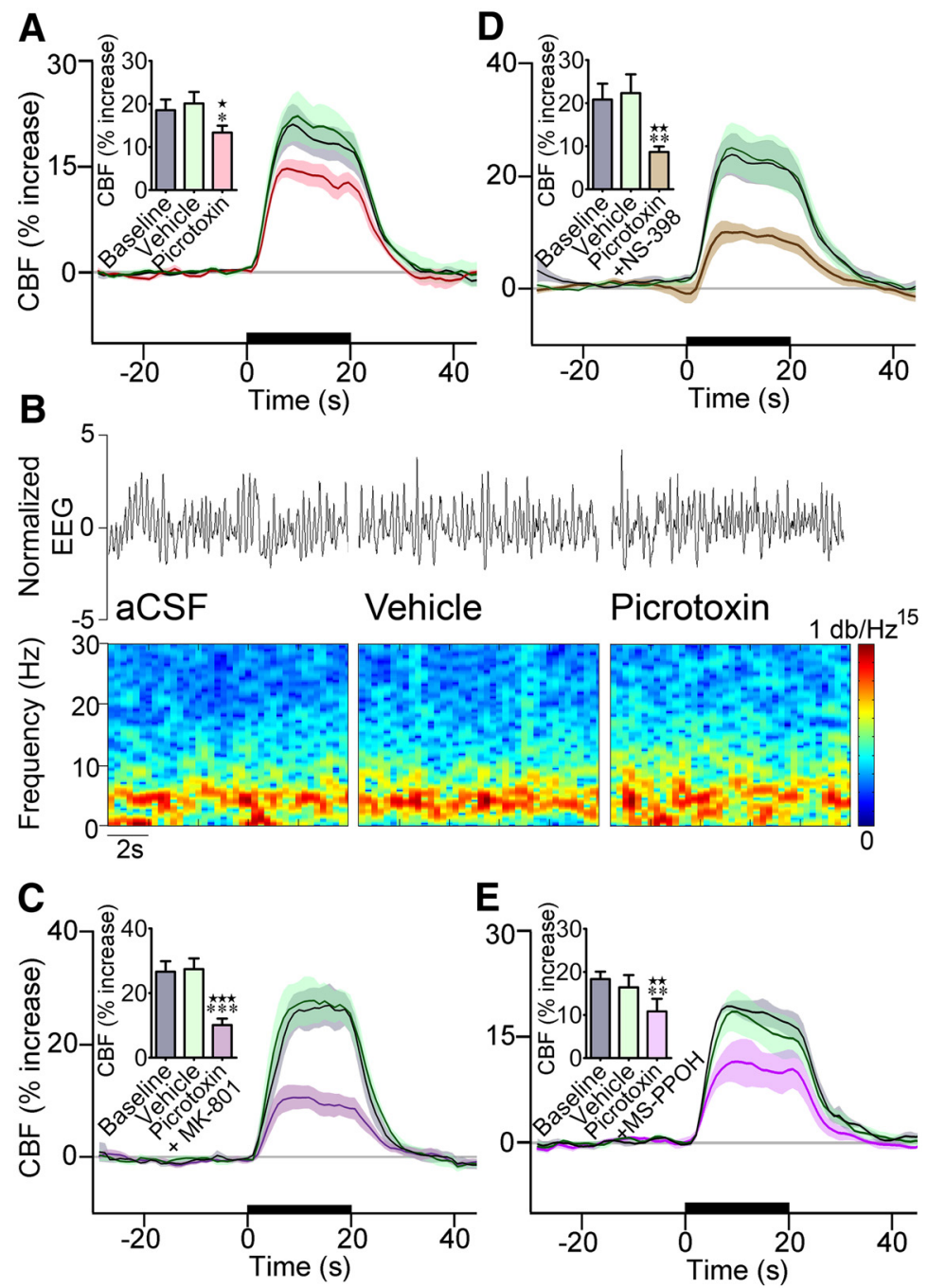

Figure 6. GABA-A receptor antagonism reduced the CBF response to whisker stimulation. $A$, One second average CBF responses to whisker stimulation measured at baseline, following vehicle or GABA-A receptor blockade after picrotoxin administration. Intracisternal injection of picrotoxin $(\boldsymbol{A}, n=7)$ significantly reduced ( $~ 31 \%)$ the evoked CBF response to whisker stimulation. $\boldsymbol{B}$, Representative EEG trace (top) recorded from a single rat during baseline, vehicle, or picrotoxin superfusion through the cranial window. Power spectral densities (bottom) were obtained through a 1024-point short-time Fourier transform, using time windows of $1 \mathrm{~s}$ with $75 \%$ overlap. The frequency band from 0 to $30 \mathrm{~Hz}$ was normalized in amplitude from 0 to 1 and equalized with an exponential function with exponent 0.15 , for better visualization. There was no change in the EEG between conditions. $C$, Combined administration of picrotoxin and MK-801 decreased the evoked CBF response $(-61 \%, n=8)$ significantly more than each compound applied individually ( $\boldsymbol{A}$, Fig. $4 A, B)$. D, Combined administration of picrotoxin and NS-398 decreased the evoked CBF response $(-52 \%, n=7)$ more than each compound applied individually, but it did not reach significance $(\boldsymbol{A}$, Fig. $4 B)$. $\boldsymbol{E}$, Similarly, combined GABA-A receptor blockade and inhibition of P450 epoxygenase with MS-PPOH decreased the evoked CBF response by $\sim 36 \%$, which compared well with the inhibition induced by each compound individually $(A, F i g .4 B)$. None of the vehicles had an effect on baseline or evoked CBF. The $20 s$ stimulation is indicated by the black line on the $x$-axis, and shaded areas denote SEM. Values are mean \pm SEM. $\star p<0.05, \star \star p<0.01, \star \star \star p<0.001$ versus baseline. ${ }^{*} p<0.05,{ }^{* *} p<0.01,{ }^{* * *} p<0.001$ by repeated-measures ANOVA.

and Stringer, 2004; Zielke et al., 2007) (Fig. 4A). These compounds blocked $\sim 40 \%$ of the CBF response after $60 \mathrm{~min}$ (Fig. $4 D$ ), supporting a role for metabolically active astrocytes in this neurovascular coupling response. Because these compounds, at least in cell cultures, can also affect neuronal responses (Hassel et al., 1995), which would question the role of astrocytes in neurovascular coupling, we further evaluated their role via inhibition of the P450 epoxygenases. This synthetic pathway is thought to be astrocytic and responsible for the release of vasodilatory eicosanoids EETs (Alkayed et al., 1996; Koehler et al., 2009) (Fig. 4A). The selective $\mathrm{P} 450$ epoxygenases inhibitor MS-PPOH signifi- cantly diminished the perfusion response $(-39.0 \pm 4.5 \%, p<0.001)$ (Fig. $4 B$ ), a reduction remarkably similar to that reported after superfusion of the same compound for 1 or $2 \mathrm{~h}$ over the sensory cortex (-38\%; Shi et al., 2008). Considering that astrocytes also express glutamate and GABA-A receptors (Conti et al., 1997; Cahoy et al., 2008), which activation by selective agonists induces vasodilatation independently of spiking activity (Fergus and Lee, 1997; Zonta et al., 2003; Lovick et al., 2005), we examined the relationship between EETs and excitatory and inhibitory neurotransmission. We coadministered MS-PPOH with MK-801 or picrotoxin and found no additive decline on the CBF response $(-40.7 \pm 4.5 \%, p<$ 0.05 , or $36.3 \pm 7.5 \%, p<0.01$ ) (Figs. $4 B$, $5 C, 6 E)$, which suggests that EETs possibly act as signaling intermediaries for both pyramidal cells and GABA interneurons.

\section{Discussion}

Our anatomical observations show that pyramidal cells that contain the rate-limiting prostanoid synthesizing enzyme COX-2 and GABA interneurons that express VIP or ChAT sculpt the hemodynamic response to whisker stimulation. Additionally, our pharmacological data demonstrate that neuronal release of glutamate, COX-2 prostanoids, and GABA, but not VIP or ACh, are essential for the full expression of the $\mathrm{CBF}$ response and that metabolically active astrocytes participate in this response, presumably through the release of EETs (Fig. 8 ). These findings indicate that the vascular response is driven by enhanced activity, partly due to GABA-A-mediated synchronization of cortical network, of excitatory pyramidal cells that release glutamate and COX-2 products. We conclude that pyramidal neurons act as "neurogenic hubs" in neurovascular coupling to sensory input.

\section{Identity of the cortical neuronal circuitry recruited by whisker stimulation}

We show that CBF increases evoked by sensory stimulation not only matched with c-Fos upregulation as shown for BOLD responses (Lu et al., 2004), but that c-Fos induction occurred in specific subsets of excitatory and inhibitory neurons in layers II/III and IV. Notwithstanding the dominant labeling of pyramidal and spiny stellate cells (Filipkowski et al., 2000; Staiger et al., 2000, 2002), our doubleimmunohistochemical data established that numerous recruited cells, located mainly in layers II/III, corresponded to COX-2 pyramidal cells. Consistent with the direct thalamic afferent input (Staiger et al., 1996b) of the overlapping populations of VIP- and ChAT-expressing GABA interneurons (Chédotal et al., 1994), we observed robust c-Fos induction in these cells throughout layers 


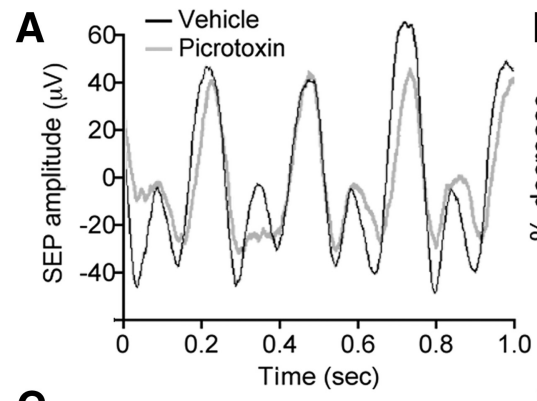

C
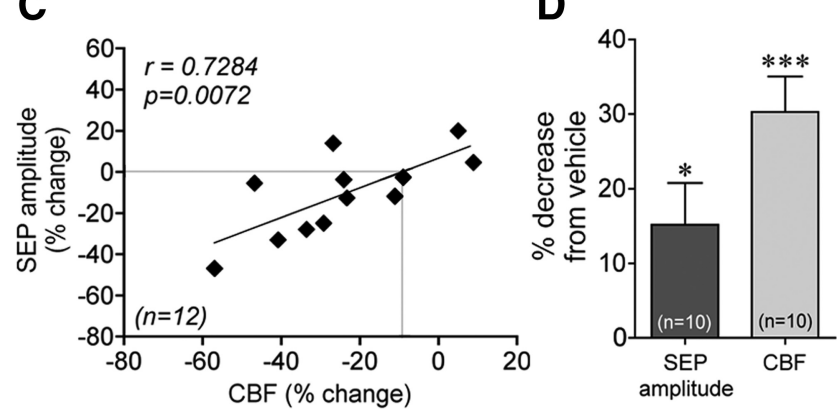

Figure 7. GABA-A receptor blockade with picrotoxin reduced the sensory-evoked increases in cortical activity and CBF. $A$, Representative somatosensory evoked potentials (SEP) induced by stimulation of the whiskers at $4 \mathrm{~Hz}$ under vehicle and picrotoxin. $\boldsymbol{B}$, Quantification of the decreases in SEP amplitude and evoked CBF responses induced by picrotoxin compared with vehicle when all rats were included in the analysis $(n=12)$, including two that did not respond to picrotoxin based on no CBF reduction. $C$, The changes in the evoked CBF responses and SEP amplitudes induced by picrotoxin were significantly correlated (Pearson correlation, $r=$ $0.7284, p<0.01, n=12)$. Note that $0 \%$ change in cortical activity was associated with a small reduction of $C B F(9.4 \%$, intercept of gray line on $x$-axis), suggesting a possible effect of picrotoxin on vascular GABA-A receptors (see text). $D$, When only rats that showed decreases in the evoked CBF response under picrotoxin ( $n=10$ of 12 ) were included in the analysis, the SEP amplitudes were significantly reduced compared with vehicle. ${ }^{*} p<0.05,{ }^{* *} p<0.01,{ }^{* * *} p<$ 0.001 , by paired Student's $t$ test.

II-IV of the activated barrels in both awake and anesthetized rats. As stimulus-induced c-Fos expression depends on various factors, but largely on firing patterns (Fields et al., 1997; Guo et al., 2007), this induction likely reflects a strong $\mathrm{Ca}^{2+}$ influx achieved by the bursting behavior described for both glutamatergic and VIP/ChAT neurons (Porter et al., 1998; de Kock and Sakmann, 2008; Karagiannis et al., 2009).

In contrast, we found no c-Fos in PV interneurons that receive strong thalamic afferents (Staiger et al., 1996a; Porter et al., 2001) and in the group of SOM/NOS interneurons that frequently express calbindin (Kubota et al., 1994; Gonchar and Burkhalter, 1997). Because c-Fos expression in PV and calbindin interneurons is induced by exploration of a novel environment (Bertini et al., 2002; Staiger et al., 2002), our experimental paradigm in pretrained and restrained or anesthetized rats may be unsuited for c-Fos upregulation in these interneurons (Staiger, 2006). Additionally, the lack of c-Fos in PV and SOM/NOS interneurons could result from their silencing by the inhibitory drive imposed by the recruited VIP cells that innervate both PV and calbindin interneurons (Staiger et al., 2004; Dávid et al., 2007) (Fig. 8). Such a scenario was recently recognized in head-restrained mice whereby fast-spiking, PV-containing, GABA interneurons markedly reduced their firing rate during active whisking, whereas that of nonfast spiking cells, which encompass VIP interneurons, greatly increased, making these interneurons the dominant source of cortical inhibition during whisking (Gentet et al., 2010). Another contributing factor could be that PV neurons

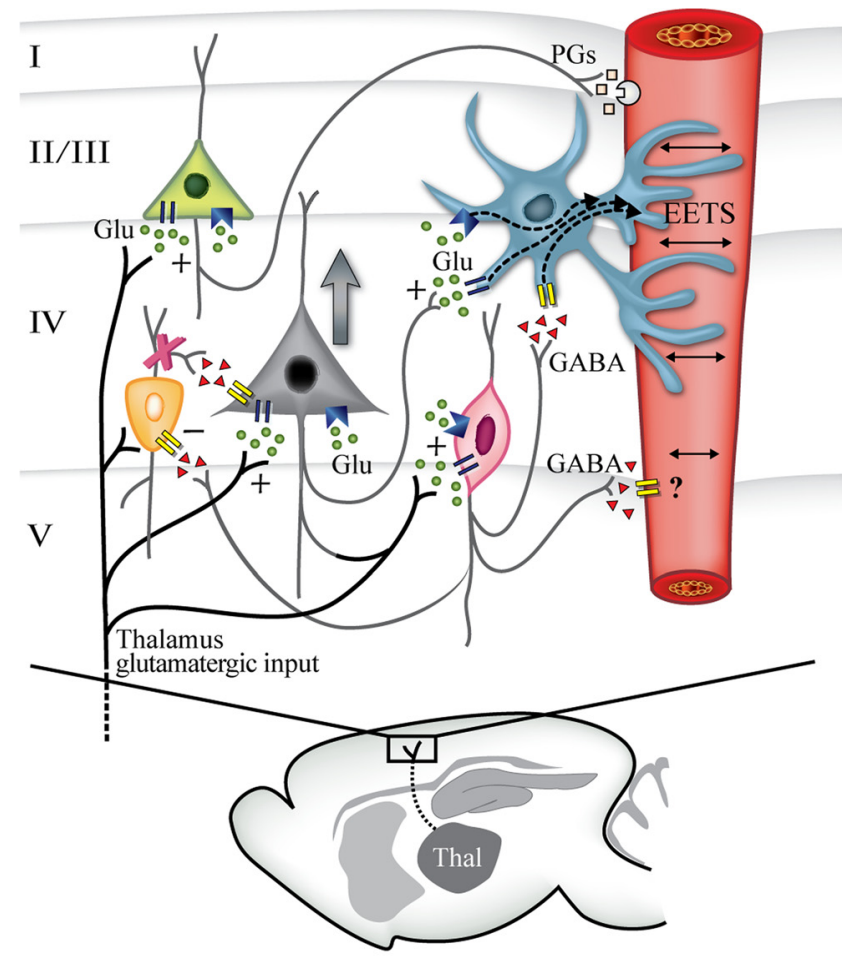 ○ Glutam
$\nabla$ GABA
$\square$ PG
$\downarrow \mathrm{PV}$ interneuron
$\square$ Pyramidal cell
VIP/ChAT interneuron
Astrocyte

Figure 8. Schematic representation of the activated neuronal populations - identified with c-Fos - in the barrel cortex following whisker stimulation and how the different neuronal populations contribute to the evoked CBF response. Sensory thalamocortical glutamatergic afferents recruit pyramidal cells, including those that contain COX-2. These activated cells can then affect $\mathrm{CBF}$ either directly by the release of COX-2-derived dilatory prostaglandins (PGs) or indirectly by astrocytic release of EETs following activation of the P450 epoxygenase pathway, likely via mGluRs. Parallel activation of GABA interneurons that colocalize VIP and/or ChAT would modulate pyramidal cell excitation, in part, by silencing (-) PV and calbindin GABA interneurons, which would disinhibit pyramidal cells and enhance cortical activity (large gray arrow). GABA interneurons could also activate the EET pathway in astrocytes through GABA-Amediated increase in calcium transients. The $X$ on PV interneurons reflects the blockade of their inhibitory drive on pyramidal cells exerted by the recruited VIP/ChAT interneurons, which results in disinhibition of pyramidal cells.

receive depressing glutamatergic input from the thalamus (Tan et al., 2008). Hence, our findings, together with recent studies on different subcortical or corticocortical afferent pathways and ensuing hypermic responses (Kocharyan et al., 2008; Enager et al., 2009), emphasize that the activated cortical circuitry is both afferent and stimulus specific, as distinct subsets of cortical neurons were recruited depending on the input.

\section{Role of excitatory pyramidal cells in the stimulus-evoked hemodynamic response}

When testing in vivo the contribution of excitatory neurons in the perfusion response, we confirmed that glutamate receptor activation was necessary for the full expression of the evoked CBF response (Norup Nielsen and Lauritzen, 2001; Zonta et al., 2003; Shi et al., 2008). Novel and particularly interesting, however, was our finding that combined blockade of NMDA receptors and the COX-2 synthetic pathway resulted in a nonadditive effect on the evoked CBF response. This suggests that these pathways acted in sequence, consistent with the ability of NMDA receptors to induce the release of COX-2-derived $\mathrm{PGE}_{2}$ (Pepicelli et al., 2005). 
Together with the selective expression of COX-2 in pyramidal cells (Yamagata et al., 1993, Breder et al., 1995; this study, Figs. 2, 3 ), the stimulus-evoked c-Fos induction in these neurons (Fig. 2), the reduced CBF response in COX-2 $2^{-1-}$ mice (Niwa et al., 2000), and the visualization of COX-2 processes in contact with cortical microvessels (H. Wang et al., 2005), our findings strongly argue for a primary role of vasodilator prostanoids, possibly $\mathrm{PGE}_{2}$, released from COX-2 pyramidal cells in the hyperemic response to whisker stimulation. The higher levels of neuronal than astroglial NMDA receptors (Cauli et al., 2000; Cahoy et al., 2008), whose antagonism did not impair astrocytic recruitment evoked by whisker stimulation (X. Wang et al., 2006), further suggest that prostanoid release results mainly from activation of neuronal NMDA receptors.

\section{Role of inhibitory interneurons in the stimulus-evoked hemodynamic response}

When assessing the contribution of inhibitory neurons, we found a role for GABA, acting through GABA-A receptors, in the evoked CBF response to sensory stimulation. Because VIP or $\mathrm{mACh}$ receptor antagonists failed to alter the whisker-evoked $\mathrm{CBF}$ response, we conclude that GABA, and not VIP or ACh, released from the activated interneurons is involved. The counterintuitive reduced CBF response after GABA-A receptor blockade resulted from altered inhibition of the activated cortical network, as shown by the decreased SEP amplitudes under picrotoxin. These findings indicate that GABA-A receptor blockade with picrotoxin, at the dose used in the current study, suppresses the inhibitory drive of the recruited VIP/ChAT interneurons on PV and calbindin interneurons, the main inhibitors of excitatory pyramidal cells (Dávid et al., 2007; Freund and Katona, 2007). This would result in net inhibition of pyramidal cells and lessen activation of the barrel to sensory stimulus, as supported by the picrotoxin-induced decreases in cortical SEP and activity-evoked CBF responses (Fig. 7). These findings indicate that synchronization of pyramidal cells is required for an optimal functional hyperemic response. Moreover, they imply that most of the vascular effects are mediated by changes in glutamate and COX-2 messengers release from pyramidal cells, rather than direct effects of GABA on cortical microvessels. Indeed, analysis of the picrotoxin-induced changes in cortical activity and CBF responses suggest that only a small part of the $\mathrm{CBF}$ change was unrelated to decrease in cortical activity $(\sim 9 \%)$ (Fig. $7 C)$. Such a conclusion is also supported by the limited vasomotor effect observed in cortical slices after bath application of GABA-A agonists (Fergus and Lee, 1997) or evoked firing of GABA interneurons (Cauli et al., 2004). Of interest, combined NMDA and GABA-A receptor antagonism cooperatively impairs both gamma oscillation (Cardin et al., 2009) and functional hyperemia (this study) in the barrel cortex, further emphasizing the role of neuronal synchronization in functional hyperemia, a response previously suggested to be initiated by the firing of inhibitory interneurons (Niessing et al., 2005).

\section{Astroglial modulators of the hemodynamic response to whisker stimulation}

NMDA and mGlu receptors (Lalo et al., 2006; Schipke et al., 2008) as well as GABA-A receptors (Nilsson et al., 1993; Fraser et al., 1995; Meier et al., 2008) increase intracellular $\mathrm{Ca}^{2+}$ in astrocytes, a key mechanism in the release of vasoactive messengers (Carmignoto and Gómez-Gonzalo, 2010). We found metabolically active astrocytes and EETs, which are reportedly exclusively located in the astrocytic compartment (Alkayed et al., 1996; for review, see Koehler et al., 2009), to account for $\sim 40 \%$ of the hyperemic response. Moreover, as reported for mGluRs (Shi et al., 2008), we found no additive-reducing effect on the CBF response after combined inhibition of P450 epoxygenase and NMDA or GABA-A receptors. Together, these data suggest that EETs synthesis and release are downstream to changes in cortical activity that results from activation of both excitatory and inhibitory neurons. Our findings of rare astroglial expression of COX-1 and intact CBF after selective COX-1 inhibition with SC-560 conclusively support the original work in mice with pharmacological or genetic inhibition of COX-1 (Niwa et al., 2001). Consequently, although they have been implicated in baseline $\mathrm{CBF}$ and in the $\mathrm{CBF}$ response to selected vasodilators (Niwa et al., 2001) or that evoked by direct astrocytic stimulation (Takano et al., 2006), our results unambiguously show that COX-1 products are not involved in the hyperemic response to whisker stimulation.

\section{Conclusion}

The present study demonstrates that enhanced activity in a highly specific network of excitatory and inhibitory neurons determines the hyperemic response to whisker stimulation, and that the vascular response is largely mediated by the release of dilatory prostanoids from COX-2 pyramidal cells and EETs, most probably from astrocytes following their activation by glutamate or GABA neurons. These mechanisms do not exclude the contribution of other neuronal or metabolic factors, such as adenosine and nitric oxide (Dirnagl et al., 1994; Kitaura et al., 2007; Koehler et al., 2009), which were not part of the present investigation. We conclude that GABA interneurons are important in neurovascular coupling primarily through modulation of excitatory pyramidal cell output, making pyramidal cells the core neuronal mediators of the hemodynamic response either directly or through astrocyte signaling (Fig. 8).

\section{References}

Alkayed NJ, Narayanan J, Gebremedhin D, Medhora M, Roman RJ, Harder DR (1996) Molecular characterization of an arachidonic acid epoxygenase in rat brain astrocytes. Stroke 27:971-979.

Angenstein F, Kammerer E, Scheich H (2009) The BOLD response in the rat hippocampus depends rather on local processing of signals than on the input or output activity. A combined functional MRI and electrophysiological study. J Neurosci 29:2428-2439.

Aronoff R, Petersen CC (2008) Layer, column and cell-type specific genetic manipulation in mouse barrel cortex. Front Neurosci 2:64-71.

Baude A, Nusser Z, Roberts JD, Mulvihill E, McIlhinney RA, Somogyi P (1993) The metabotropic glutamate receptor (mGluR1 alpha) is concentrated at perisynaptic membrane of neuronal subpopulations as detected by immunogold reaction. Neuron 11:771-787.

Bertini G, Peng ZC, Fabene PF, Grassi-Zucconi G, Bentivoglio M (2002) Fos induction in cortical interneurons during spontaneous wakefulness of rats in a familiar or enriched environment. Brain Res Bull 57:631-638.

Berwick J, Johnston D, Jones M, Martindale J, Martin C, Kennerley AJ, Redgrave P, Mayhew JE (2008) Fine detail of neurovascular coupling revealed by spatiotemporal analysis of the hemodynamic response to single whisker stimulation in rat barrel cortex. J Physiol 99:787-798.

Breder CD, Dewitt D, Kraig RP (1995) Characterization of inducible cyclooxygenase in rat brain. J Comp Neurol 355:296-315.

Cahoy JD, Emery B, Kaushal A, Foo LC, Zamanian JL, Christopherson KS, Xing Y, Lubischer JL, Krieg PA, Krupenko SA, Thompson WJ, Barres BA (2008) A transcriptome database for astrocytes, neurons, and oligodendrocytes: a new resource for understanding brain development and function. J Neurosci 28:264-278.

Cardin JA, Carlén M, Meletis K, Knoblich U, Zhang F, Deisseroth K, Tsai LH, Moore CI (2009) Driving fast-spiking cells induces gamma rhythm and controls sensory responses. Nature 459:663-667. 
Carmignoto G, Gómez-Gonzalo M (2010) The contribution of astrocyte signalling to neurovascular coupling. Brain Res Rev 63:138-148.

Cauli B, Hamel E (2010) Revisiting the role of neurons in neurovascular coupling. Front Neuroenergetics 2:9.

Cauli B, Audinat E, Lambolez B, Angulo MC, Ropert N, Tsuzuki K, Hestrin S, Rossier J (1997) Molecular and physiological diversity of cortical nonpyramidal cells. J Neurosci 17:3894-3906.

Cauli B, Porter JT, Tsuzuki K, Lambolez B, Rossier J, Quenet B, Audinat E (2000) Classification of fusiform neocortical interneurons based on unsupervised clustering. Proc Natl Acad Sci U S A 97:6144-6149.

Cauli B, Tong XK, Rancillac A, Serluca N, Lambolez B, Rossier J, Hamel E (2004) Cortical GABA interneurons in neurovascular coupling: relays for subcortical vasoactive pathways. J Neurosci 24:8940-8949.

Chédotal A, Cozzari C, Faure MP, Hartman BK, Hamel E (1994) Distinct choline acetyltransferase (ChAT) and vasoactive intestinal polypeptide (VIP) bipolar neurons project to local blood vessels in the rat cerebral cortex. Brain Res 646:181-193.

Conti F, Minelli A, DeBiasi S, Melone M (1997) Neuronal and glial localization of NMDA receptors in the cerebral cortex. Mol Neurobiol 14:1-18.

Cox SB, Woolsey TA, Rovainen CM (1993) Localized dynamic changes in cortical blood flow with whisker stimulation corresponds to matched vascular and neuronal architecture of rat barrels. J Cereb Blood Flow Metab 13:899-913.

Dávid C, Schleicher A, Zuschratter W, Staiger JF (2007) The innervation of parvalbumin-containing interneurons by VIP-immunopositive interneurons in the primary somatosensory cortex of the adult rat. Eur J Neurosci 25:2329-2340.

Deininger MH, Schluesener HJ (1999) Cyclooxygenases-1 and -2 are differentially localized to microglia and endothelium in rat EAE and glioma. J Neuroimmunol 95:202-208.

de Kock CP, Sakmann B (2008) High frequency action potential bursts ( $\geq$ $100 \mathrm{~Hz}$ ) in L2/3 and L5B thick tufted neurons in anaesthetized and awake rat primary somatosensory cortex. J Physiol 586:3353-3364.

Dirnagl U, Niwa K, Lindauer U, Villringer A (1994) Coupling of cerebral blood flow to neuronal activation: role of adenosine and nitric oxide. Am J Physiol 267:H296-H301.

Dunn AK, Devor A, Dale AM, Boas DA (2005) Spatial extent of oxygen metabolism and hemodynamic changes during functional activation of the rat somatosensory cortex. Neuroimage 27:279-290.

Enager P, Piilgaard H, Offenhauser N, Kocharyan A, Fernandes P, Hamel E, Lauritzen M (2009) Pathway-specific variations in neurovascular and neurometabolic coupling in rat primary somatosensory cortex. J Cereb Blood Flow Metab 29:976-986.

Ferezou I, Bolea S, Petersen CC (2006) Visuallizing the cortical representation of the whisker touch: voltage-sensitive dye imaging in freely moving mice. Neuron 50:617-629.

Fergus A, Lee KS (1997) GABAergic regulation of cerebral microvascular tone in the rat. J Cereb Blood Flow Metab 17:992-1003.

Fields RD, Eshete F, Stevens B, Itoh K (1997) Action potential-dependent regulation of gene expression: temporal specificity in $\mathrm{Ca} 2+$, cAMPresponsive element binding proteins, and mitogen-activated protein kinase signaling. J Neurosci 17:7252-7266.

Filipkowski RK, Rydz M, Berdel B, Morys J, Kaczmarek L (2000) Tactile experience induces c-Fos expression in rat barrel cortex. Learn Mem 7:116-122.

Fisher RA, Yates F (1963) Statistical tables for biological, agricultural and medical research. Edinburgh: Oliver and Boyd.

Fonnum F, Johnsen A, Hassel B (1997) Use of fluorocitrate and fluoroacetate in the study of brain metabolism. Glia 21:106-113.

Fraser DD, Duffy S, Angelides KJ, Perez-Velazquez JL, Kettenmann H, MacVicar BA (1995) GABAA/benzodiazepine receptors in acutely isolated hippocampal astrocytes. J Neurosci 15:2720-2732.

Freund TF, Katona I (2007) Perisomatic inhibition. Neuron 56:33-42.

Gajewska A, Wolińska-Witort E, Kochman K (2005) Vasoactive intestinal peptide modulates luteinizing hormone subunit gene expression in the anterior pituitary in female rat. Brain Res Bull 67:319-326.

Gallopin T, Geoffroy H, Rossier J, Lambolez B (2006) Cortical sources of CRF, NKB, and CCK and their effects on pyramidal cells in the neocortex. Cereb Cortex 16:1440-1452.

Gentet LJ, Avermann M, Matyas F, Staiger JF, Petersen CC (2010) Membrane potential dynamics of GABAergic neurons in the barrel cortex of behaving mice. Neuron 65:422-435.
Gerrits RJ, Stein EA, Greene AS (1998) Laser-Doppler flowmetry utilizing a thinned skull cranial window preparation and automated stimulation. Brain Res Brain Res Protoc 3:14-21.

Gonchar Y, Burkhalter A (1997) Three distinct families of GABAergic neurons in rat visual cortex. Cereb Cortex 7:347-358.

Gordon GR, Choi HB, Rungta RL, Ellis-Davies GC, MacVicar BA (2008) Brain metabolism dictates the polarity of astrocyte control over arterioles. Nature 456:745-749.

Gsell W, Burke M, Wiedermann D, Bonvento G, Silva AC, Dauphin F, Bührle C, Hoehn M, Schwindt W (2006) Differential effects of NMDA and AMPA glutamate receptors on functional magnetic resonance imaging signals and evoked neuronal activity during forepaw stimulation of the rat. J Neurosci 26:8409-8416.

Guo YP, Sun X, Li C, Wang NQ, Chan YS, He J (2007) Corticothalamic synchronization leads to c-Fos expression in the auditory thalamus. Proc Natl Acad Sci U S A 104:11802-11807.

Hassel B, Westergaard N, Schousboe A, Fonnum F (1995) Metabolic differences between primary cultures of astrocytes and neurons from cerebellum and cerebral cortex. Effects of fluorocitrate. Neurochem Res 20: 413-420.

Heiss JE, Katz Y, Ganmor E, Lampl I (2008) Shift in the balance between excitation and inhibition during sensory adaptation of S1 neurons. J Neurosci 28:13320-13330.

Houades V, Koulakoff A, Ezan P, Seif I, Giaume C (2008) Gap junctionmediated astrocytic networks in the mouse barrel cortex. J Neurosci 28:5207-5217.

Jones M, Berwick J, Johnston D, Mayhew J (2001) Concurrent optical imaging spectroscopy and laser-Doppler flowmetry: the relationship between blood flow, oxygenation, and volume in rodent barrel cortex. Neuroimage 13:1002-1015.

Kafitz KW, Meier SD, Stephan J, Rose CR (2008) Developmental profile and properties of sulforhodamine 101—labeled glial cells in acute brain slices of rat hippocampus. J Neurosci Methods 169:84-92.

Karagiannis A, Gallopin T, Dávid C, Battaglia D, Geoffroy H, Rossier J, Hillman EM, Staiger JF, Cauli B (2009) Classification of NPY-expressing neocortical interneurons. J Neurosci 29:3642-3659.

Kitaura H, Uozumi N, Tohmi M, Yamazaki M, Sakimura K, Kudoh M, Shimizu T, Shibuki K (2007) Roles of nitric oxide as a vasodilator in neurovascular coupling of mouse somatosensory cortex. Neurosci Res 59:160-171.

Kocharyan A, Fernandes P, Tong XK, Vaucher E, Hamel E (2008) Specific subtypes of cortical GABA interneurons contribute to the neurovascular coupling response to basal forebrain stimulation. J Cereb Blood Flow Metab 28:221-231.

Koehler RC, Roman RJ, Harder DR (2009) Astrocytes and the regulation of cerebral blood flow. Trends Neurosci 32:160-169.

Kubota Y, Hattori R, Yui Y (1994) Three distinct subpopulations of GABAergic neurons in rat frontal agranular cortex. Brain Res 649:159-173.

Lalo U, Pankratov Y, Kirchhoff F, North RA, Verkhratsky A (2006) NMDA receptors mediate neuron-to-glia signaling in mouse cortical astrocytes. J Neurosci 26:2673-2683.

Lambolez B, Audinat E, Bochet P, Crépel F, Rossier J (1992) AMPA receptor subunits expressed by single Purkinje cells. Neuron 9:247-258 .

Lauritzen M, Gold L (2003) Brain function and neurophysiological correlates of signals using in functional neuroimaging. J Neurosci 23:3972-3980.

Leithner C, Royl G, Offenhauser N, Füchtemeier M, Kohl-Bareis M, Villringer A, Dirnagl U, Lindauer U (2010) Pharmacological uncoupling of activation induced increases in $\mathrm{CBF}$ and $\mathrm{CMRO}(2)$. J Cereb Blood Flow Metab 30:311-322.

Lévesque M, Langlois JM, Lema P, Courtemanche R, Bilodeau GA, Carmant L (2009) Synchronized gamma oscillations $(30-50 \mathrm{~Hz})$ in the amygdalo-hippocampal network in relation with seizure propagation and severity. Neurobiol Dis 35:209-218.

Lian XY, Stringer JL (2004) Inhibition of aconitase in astrocytes increases the sensitivity to chemical convulsants. Epilepsy Res 60:41-52.

Logothetis NK, Pauls J, Augath M, Trinath T, Oeltermann A (2001) Neurophysiological investigation of the basis of the fMRI signal. Nature 412:150-157.

Lovick TA, Brown LA, Key BJ (2005) Neuronal activity-related coupling in cortical arterioles: involvement of astrocyte-derived factors. Exp Physiol 90:131-140. 
Lu H, Patel S, Luo F, Li SJ, Hillard CJ, Ward BD, Hyde JS (2004) Spatial correlations of laminar BOLD and CBV responses to rat whisker stimulation with neuronal activity localized by Fos expression. Magn Reson Med 52:1060-1068.

Maier DL, McCasland JS (1997) Calcium-binding protein phenotype defines metabolically distinct groups of neurons in barrel cortex of behaving hamsters. Exp Neurol 145:71-80.

Martin C, Berwick J, Johnston D, Zheng Y, Martindale J, Port M, Redgrave P, Mayhew J (2002) Optical imaging spectroscopy in the unanaesthetised rat. J Neurosci Methods 120:25-34.

Meier SD, Kafitz KW, Rose CR (2008) Developmental profile and mechanisms of GABA-induced calcium signaling in hippocampal astrocytes. Glia 56:1127-1137.

Nakao Y, Gotoh J, Kuang TY, Cohen DM, Pettigrew KD, Sokoloff L (1999) Cerebral blood flow responses to somatosensory stimulation are unaffected by scopolamine in unanesthetized rat. J Pharmacol Exp Ther 290:929-934.

Niessing J, Ebisch B, Schmidt KE, Niessing M, Singer W, Galuske RA (2005) Hemodynamic signals correlate tightly with synchronized gamma oscillations. Science 309:948-951.

Nilsson M, Eriksson PS, Rönnbäck L, Hansson E (1993) GABA induces $\mathrm{Ca} 2+$ transients in astrocytes. Neuroscience 54:605-614.

Nimmerjahn A, Kirchhoff F, Kerr JN, Helmchen F (2004) Sulforhodamine 101 as a specific marker of astroglia in the neocortex in vivo. Nat Methods $1: 31-37$.

Niwa K, Araki E, Morham SG, Ross ME, Iadecola C (2000) Cyclooxygenase-2 contributes to functional hyperemia in whiskerbarrel cortex. J Neurosci 20:763-770.

Niwa K, Haensel C, Ross ME, Iadecola C (2001) Cyclooxygenase-1 participates in selected vasodilator responses of the cerebral circulation. Circ Res 88:600-608.

Norup Nielsen A, Lauritzen M (2001) Coupling and uncoupling of activitydependent increases of neuronal activity and blood flow in rat somatosensory cortex. J Physiol 533:773-785.

Pepicelli O, Fedele E, Berardi M, Raiteri M, Levi G, Greco A, Ajmone-Cat MA, Minghetti L (2005) Cyclo-oxygenase-1 and -2 differently contribute to prostaglandin E2 synthesis and lipid peroxidation after in vivo activation on $\mathrm{N}$-methyl-D-aspartate receptors in rat hippocampus. J Neurochem 93:1561-1567.

Petersen CC, Grinvald A, Sakmann B (2003) Spatiotemporal dynamics of sensory responses in layer $2 / 3$ of rat barrel cortex measured in vivo by voltage-sensitive dye imaging combined with whole-cell voltage recordings and neuron reconstructions. J Neurosci 23:1298-1309.

Porter JT, Cauli B, Staiger JF, Lambolez B, Rossier J, Audinat E (1998) Properties of bipolar VIPergic interneurons and their excitation by pyramidal neurons in the rat neocortex. Eur J Neurosci 10:3617-3628.

Porter JT, Johnson CK, Agmon A (2001) Diverse types of interneurons generate thalamus-evoked feedforward inhibition in the mouse barrel cortex. J Neurosci 21:2699-2710.

Sanganahalli BG, Herman P, Hyder F (2008) Frequency-dependent tactile responses in rat brain measured by functional MRI. NMR Biomed 21:410-416.

Schipke CG, Haas B, Kettenmann H (2008) Astrocytes discriminate and selectively respond to the activity of a subpopulation of neurons within the barrel cortex. Cereb Cortex 18:2450-2459.

Shi Y, Liu X, Gebremedhin D, Falck JR, Harder DR, Koehler RC (2008) Interaction of mechanisms involving epoxyeicosatrienoic acids, adenosine receptors, and metabotropic glutamate receptors in neurovascular coupling in rat whisker barrel cortex. J Cereb Blood Flow Metab $28: 111-125$
Slanina KA, Schweitzer P (2005) Inhibition of cyclooxygenase-2 elicits a CB1-mediated decrease of excitatory transmission in rat CA1 hippocampus. Neuropharmacology 49:653-659.

Staiger JF (2006) Immediate-early gene expression in the barrel cortex. Somatosens Mot Res 23:135-146.

Staiger JF, Zilles K, Freund TF (1996a) Distribution of GABAergic elements postsynaptic to ventroposteromedial thalamic projections in layer IV of rat barrel cortex. Eur J Neurosci 8:2273-2285.

Staiger JF, Zilles K, Freund TF (1996b) Innervation of VIP-immunoreactive neurons by the ventroposteromedial thalamic nucleus in the barrel cortex of the rat. J Comp Neurol 367:194-204.

Staiger JF, Bisler S, Schleicher A, Gass P, Stehle JH, Zilles K (2000) Exploration of a novel environment leads to the expression of inducible transcription factors in barrel-related columns. Neuroscience 99:7-16.

Staiger JF, Masanneck C, Bisler S, Schleicher A, Zuschratter W, Zilles K (2002) Excitatory and inhibitory neurons express c-Fos in barrel-related columns after exploration of a novel environment. Neuroscience 109: 687-699.

Staiger JF, Masanneck C, Schleicher A, Zuschratter W (2004) Calbindincontaining interneurons are a target for VIP-immunoreactive synapses in rat primary somatosensory cortex. J Comp Neurol 468:179-189.

Takano T, Tian GF, Peng W, Lou N, Libionka W, Han X, Nedergaard M (2006) Astrocyte-mediated control of cerebral blood flow. Nat Neurosci 9:260-267.

Tanaka S, Nakamura T, Sumitani K, Takahashi F, Konishi R, Itano T, Miyamoto O (2009) Stage- and region-specific cyclooxygenase expression and effects of a selective COX-1 inhibitor in the mouse amygdale kindling model. Neurosci Res 65:79-87.

Tan Z, Hu H, Hyang ZJ, Agmon A (2008) Robust but delayed thalamocortical activation of dendritic-targeting inhibitory interneurons. Proc Natl Acad Sci U S A 105:2187-2192.

Wang H, Hitron IM, Iadecola C, Pickel VM (2005) Synaptic and vascular associations of neurons containing cyclooxygenase-2 and nitric oxide synthase in rat somatosensory cortex. Cereb Cortex 15:1250-1260.

Wang X, Lou N, Xu Q, Tian GF, Peng WG, Han X, Kang J, Takano T, Nedergaard M (2006) Astrocytic Ca2+ signaling evoked by sensory stimulation in vivo. Nat Neurosci 9:816-823.

Woolsey TA, Van der Loos H (1970) The structural organization of layer IV in the somatosensory region (SI) of the mouse cerebral cortex: the description of a cortical field composed of discrete cytoarchitectonic units. Brain Res 17:205-242.

Woolsey TA, Rovainen CM, Cox SB, Henegar MH, Liang GE, Liu D, Moskalenko YE, Sui J, Wei L (1996) Neuronal units linked to microvascular modules in cerebral cortex: response elements for imaging the brain. Cereb Cortex 6:647-660.

Yamagata K, Andreasson KI, Kaufmann WE, Barnes CA, Worley PF (1993) Expression of a mitogen-inducible cyclooxygenase in brain neurons: regulation by synaptic activity and glucocorticoids. Neuron 11:371-386.

Yermakova AV, Rollins J, Callahan LM, Rogers J, O’Banion MK (1999) Cyclooxygenase-1 in human Alzheimer and control brain: quantitative analysis of expression by microglia and CA3 hippocampal neurons. J Neuropathol Exp Neurol 58:1135-1146.

Zielke HR, Zielke CL, Baab PJ, Tildon JT (2007) Effect of fluorocitrate on cerebral oxidation of lactate and glucose in freely moving rats. J Neurochem 101:9-16.

Zonta M, Angulo MC, Gobbo S, Rosengarten B, Hossmann KA, Pozzan T, Carmignoto G (2003) Neuron-to-astrocyte signaling is central to the dynamic control of brain microcirculation. Nat Neurosci 6:43-50. 